\title{
"وعلّمَ آدم الأسماء كلها" في ميزان نظرية الرموز الثقافية
}

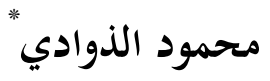

نحاول في هذه الدراسة التعرّف على معنى الآيـة الحادية والثلاثين مـن سورة البقرة،

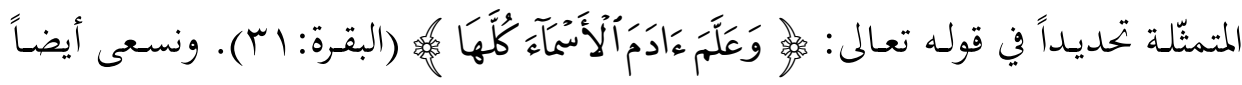
إلى الحصول على أقرب تأويل لمعناهـا، مستعينين بآراء المفسّرين، وبرؤى علوم الإنسـان والمحتمع المعاصرة. وهذه بعض تأويلات بحموعة من المفسّرين والمفكرين:

\section{أولاً: نماذج تأويلية للآية:

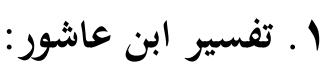

ففي كتابه تفسير "التحرير والتنوير" يُلقى الشيخ، في خمس صفحات، أضواءً على معنى هذا الجزء من الآية الحادية والثلاثين من سورة البقرة.' يشرع ابن عاشور في تفسيره بما يشبه المقدمة لمحاولة تفسيره اللاحق، فيقول: "... فيإنَّ تعليم آدم الأسماء كلَّها وإظهار

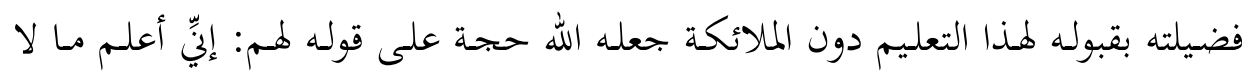

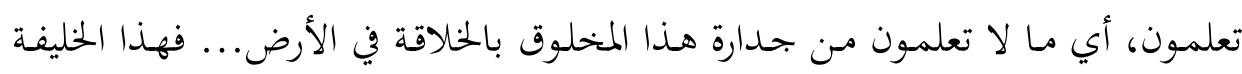

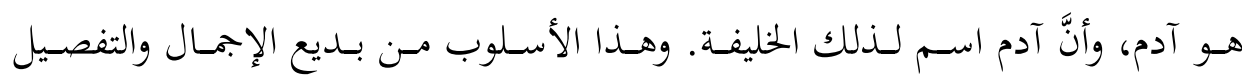
والإيجاز."

بعد ذلك يتطرّق ابن عاشور إلى معنى كلمة "آدم" في اللغات الأُخرى، مثل العبرية والفارسية وغيرهما، فيستشهد بقول الجوهري في أصل كلمة "آدم"، الذي يرى أنّ أصلها

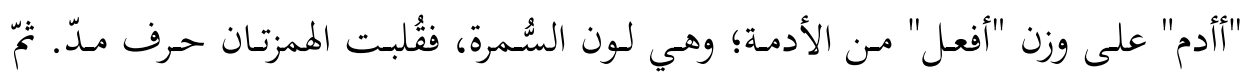

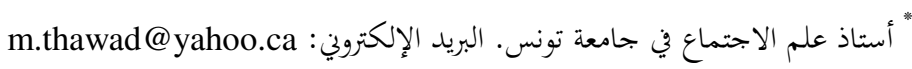

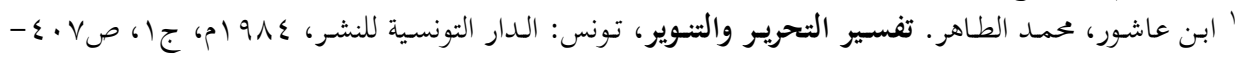


ينتقل ابن عاشور إلى شرح معنى كلمة "الأسماء" الواردة في مطلع الآية الكريمة، فيقول:

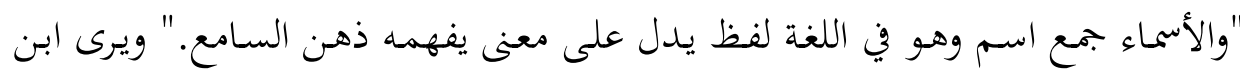

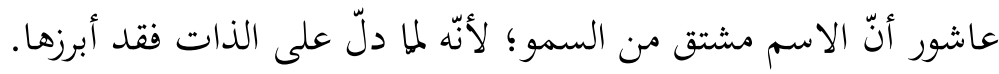

ويبدأ ابن عاشور في تفسير كلمة "الأسمـاء" -بيـت القصيد في هذا الجزءء مـ الآية

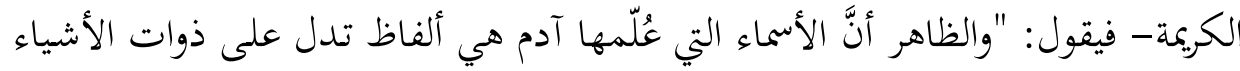

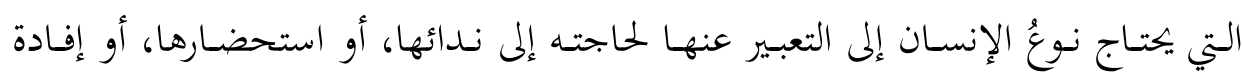

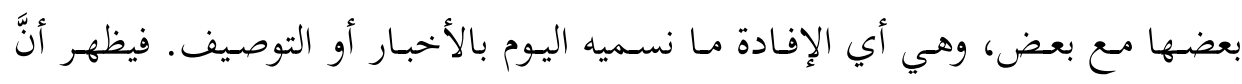

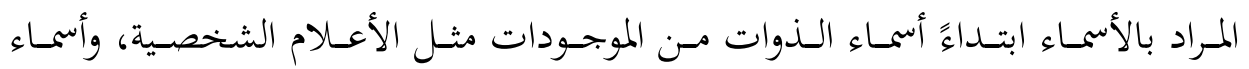

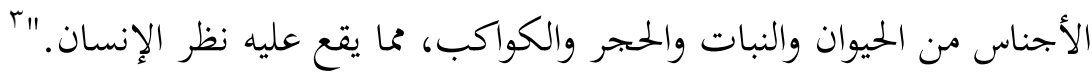

ويتحدث ابن عاشور بعد ذلك عن طرائق تعلّم آدم للأسماء، فيشير إلى أهمية دور

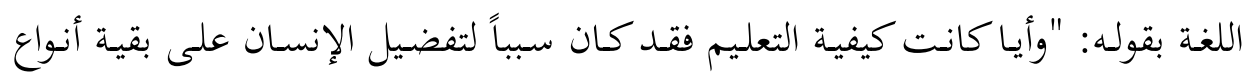
جنسه بقوة النطق وإحداث الموضوعات اللغوية للتعبير عما في الضمير."ا؛ وعلى الرغم

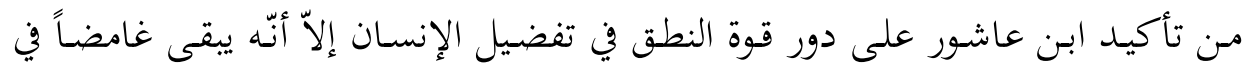

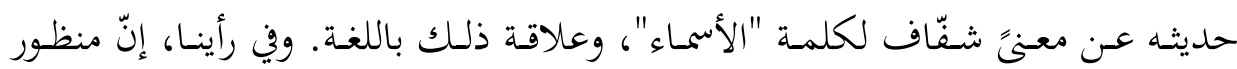

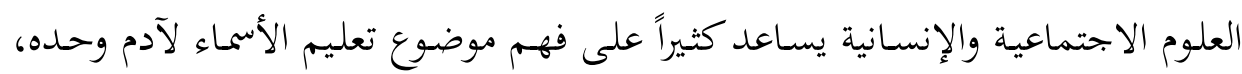

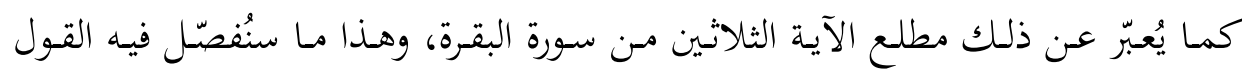

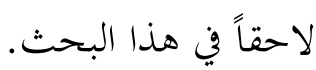

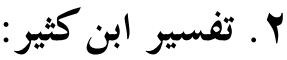

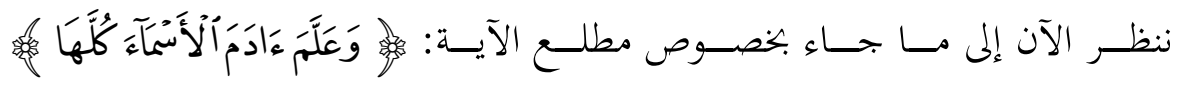
(البقرة: آץ) في تفسير شهير قـديم للقـرآن الكريم بعنوان (تفسير القـرآن العظيم) لعماد

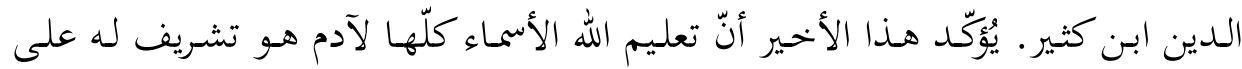
الملائكة وغيرهم. 
ويسرد ابـن كثير قائمهة بأسمـاء مَن لهم تفسير لمعنى ذلك الجـزء مـن الآيـة الكريمـة، ويخلص إلى القول بأنّ "لفظ "وعلّم آدم الأسماء كلها" يعني عنده -ولدى بقية مَن ذكر

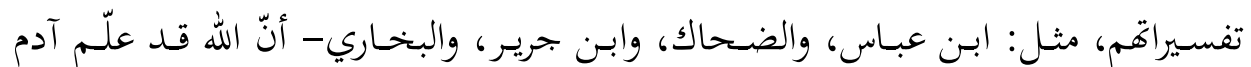

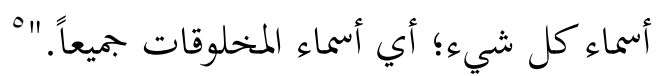
وقـد أشـار ابـن العباس إلى أنّ الله علّم آدم أسمـاء ولـده وأسمـاء الدواب، فقيـل هـذا

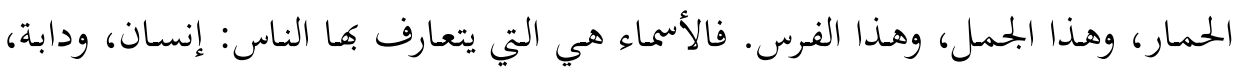
وسماء، وأرض، وسهل، وبحر، وخيل، وحمار، وأشياء ذلك من الأمم وغيرها. تيمّ يستشهد

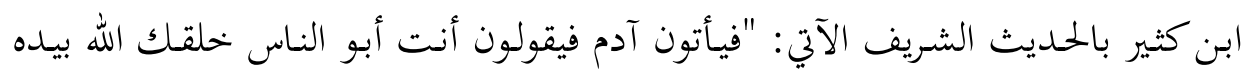
وأسجد لك ملائكته وعلمك أسماء كل شيء"، ويُعلّق على ذلك مسترسلاً: "فدل هذا

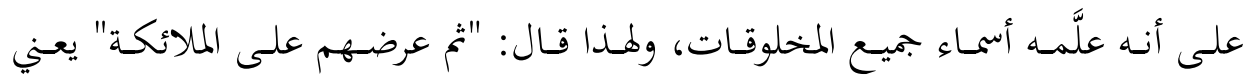
المسميات كما قال عبد الززاق عن معمر عن قتادة."

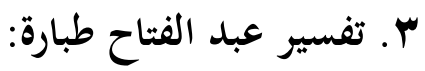

يلخص المفسّر السوري المعاصر عفيف عبد الفتاح طبارة معنى الآية الكريمة "وعلّم آدم الأسمـاء كلها" في قوله: "ألمهـه الله معرفـة ذات الأشياء التي خلقهـا ومعرفـة أسمائهـا ومنافعها." ويضيف طبارة شارحاً معنى "الأسماء كلها" بقوله: "يدل على أنه علّمه أسماء كلِّ ما خلق الله مـن المخلوقات من إنسان وحيوان ودابَّة وطيْر وغير ذلك، ويصحُّ حمل

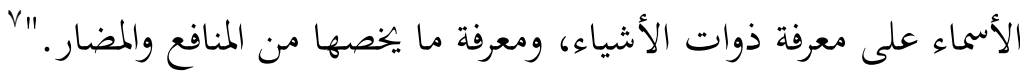
ويستشهد طبارة بما جاء في تفسير الشيخ متولي الشعراوي: "والعجيب أنَّ الطريقة التي علّم الله سبحانه وتعالى آدم بها هي الطريقة نفسها التي تتبعها البشرية إلى يومنا هذا،

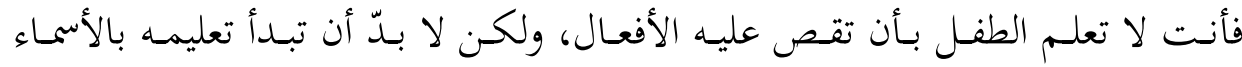

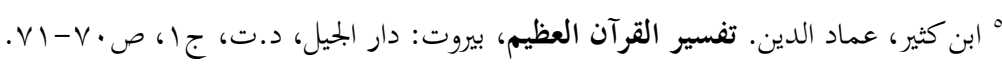

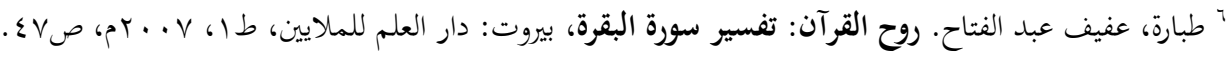

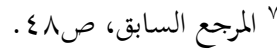


والمسـميات تقـول لـه: هـذاكـوب وهـذا جبـل وهـذه شمـس وهـذا قمـر، وبعـد أن يـتعلّم

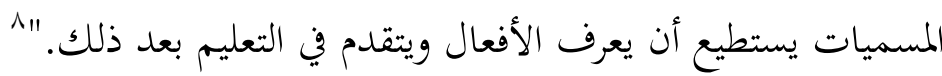

\section{ع ـ تفسير الجابري:}

لا يكاد يذكر الجحابري بخصوص معنى قوله تعالى: "وعلّم آدم الأسماء كلها" سِوى

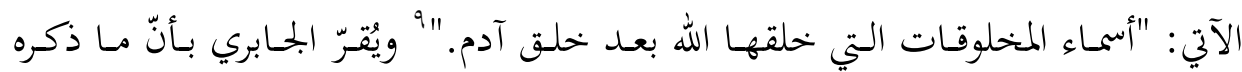

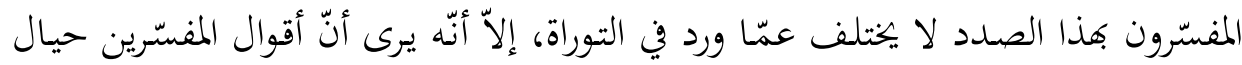

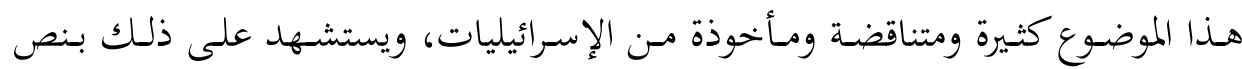

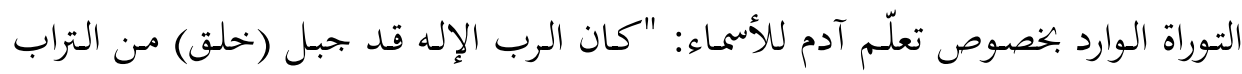

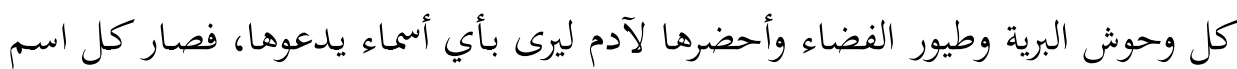

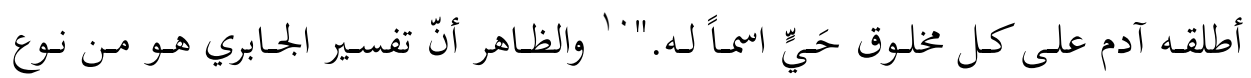
التفسير الحريف لكلمة "أسماء"، كما ذهب إلى ذلك نصل نص التوراة المشار إليه آنفاً.

وخلاصة القول مّّا ورد في كلام بعض المفسّرين والمفكرين أفّهم جميعاً لمج يحاولوا إيجاد تأويلات لمعنى كلمة "أسماء" تتجاوز دلالتها الحرفية. فحتى تفسير الشيخ متولي الشعراوي

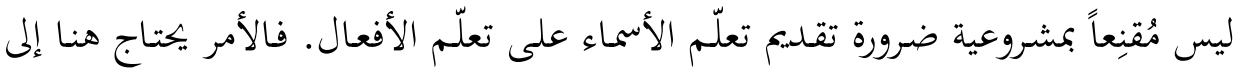

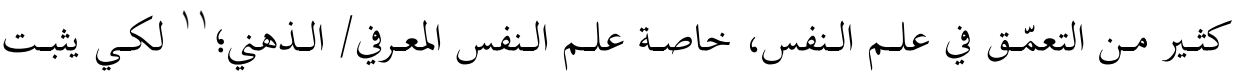

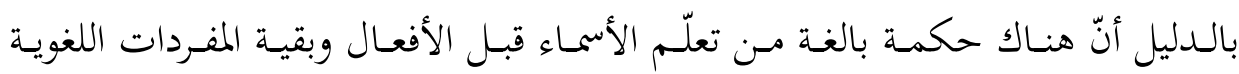
كالنعوت والحروف.

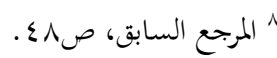

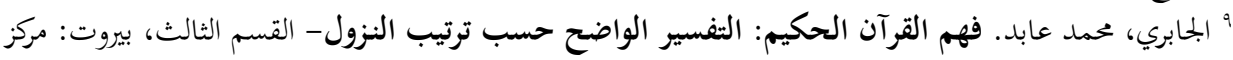

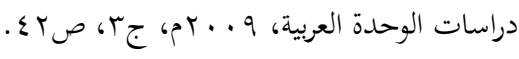

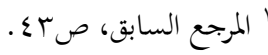

${ }^{11}$ Wilber, K. Integral Psychology: Consciousness, Spirit, Psychology, Therapy, Boston, Shambhala, 2000.

- Martin, B., Rumelhart, D. Editors. Cognitive Science, San Diago, Academic Press, 1999.

- Andresen, J., Forman, R. Editors. Cognitive Models and Spiritual Maps, Charlottesville, Imprint Academic, 2002. 
ثانياً: سبيل الفهم إلى معنى الآية

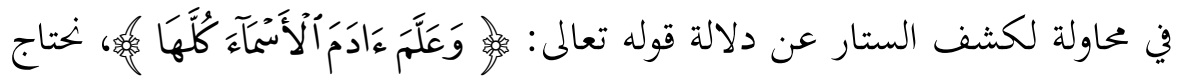

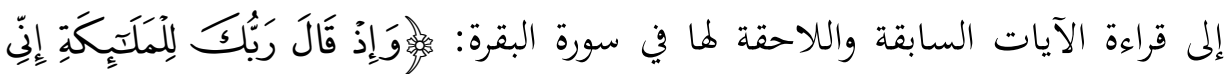

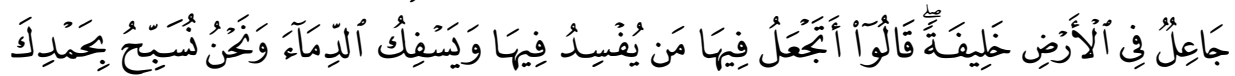

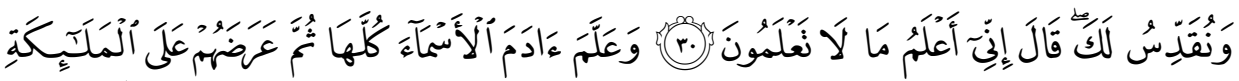

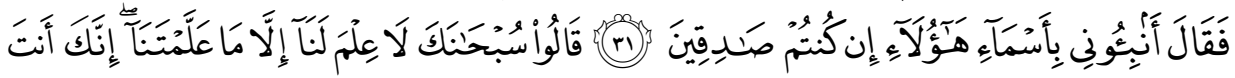

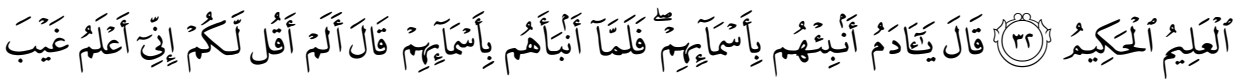

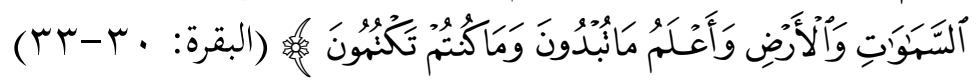
تُبرز هذه الآيات الكريمة ثلاث ميزات لآدم الإنسان، هي: تفرّده في خحلافة الله في

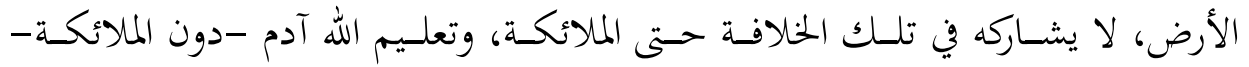

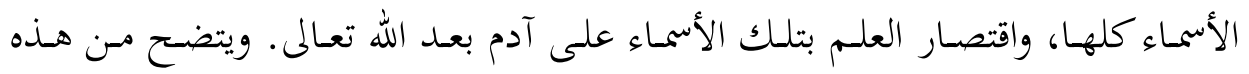

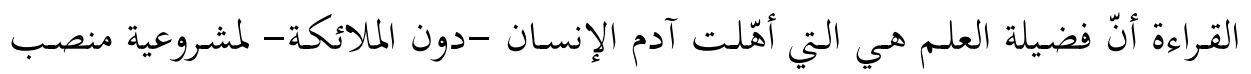

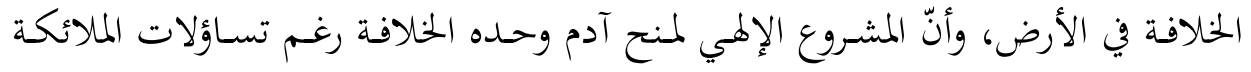

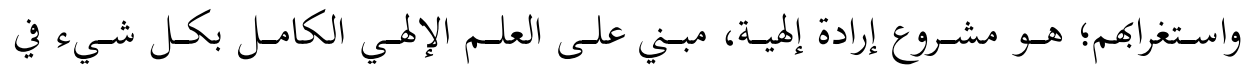

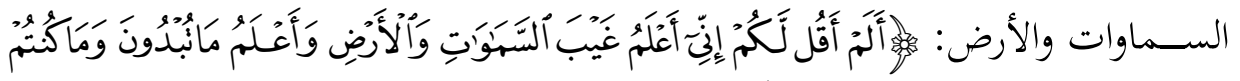

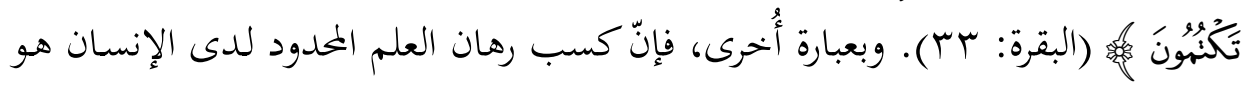

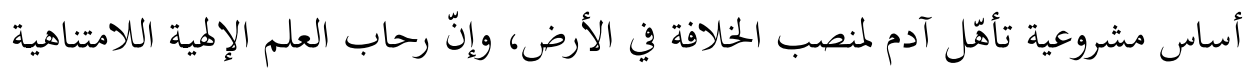
هي التي جعلت الحكمة الإلهية تُبصر ما لا تراه الملائكة في خلق آدم وتشريفه بالخلافلافة.

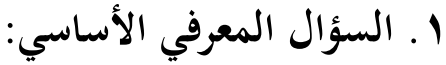

بصرف النظر عن الخارطة المعرفية التي يمكن الإفادة منها في تفسير الحكمة من تعلّم

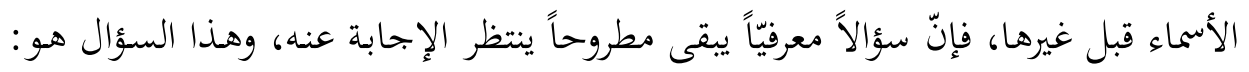

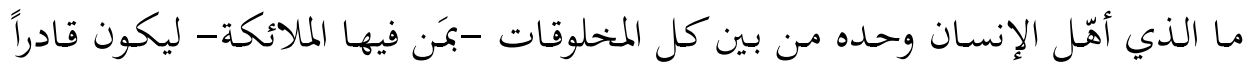

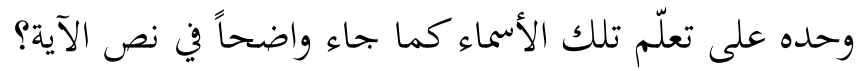




\section{r. ب نظرة العقل لأصول تميّز آدم/ الإنسان:}

رأينا بوضوح في القرآن الكريم (النقل) أنّ تميّز آدم/ الإنسان على الملائكة وتأهّله

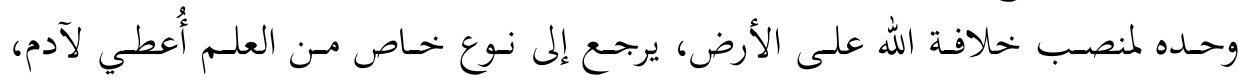

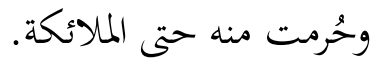

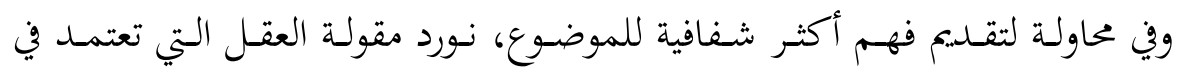

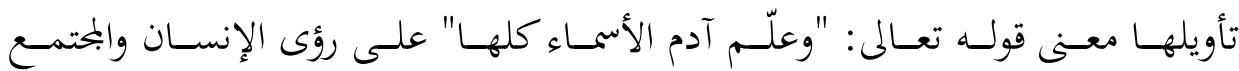

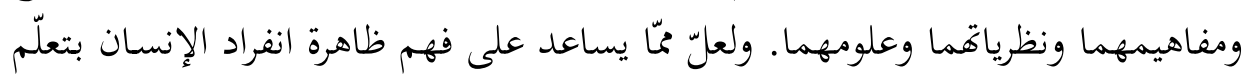

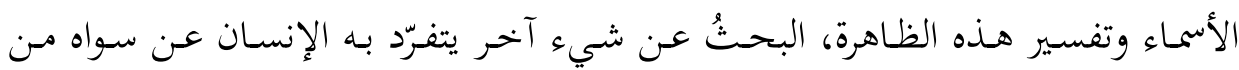

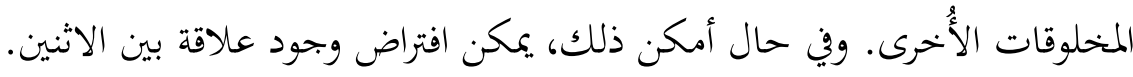

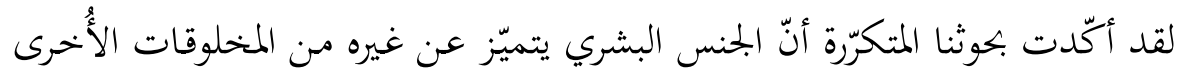

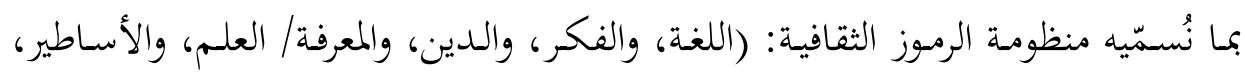

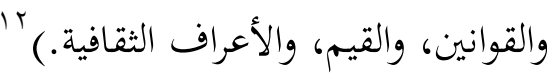

والسؤال الرئيس الذي قد يتبادر إلى الذهن، هو : مـا طبيعة العلاقة بين قدرة آدم الدئي

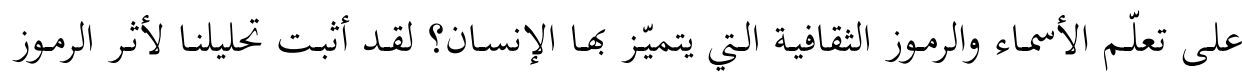

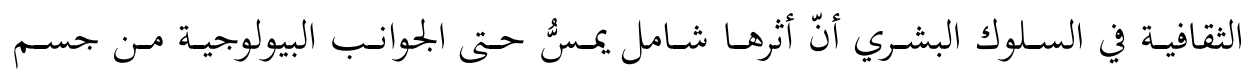

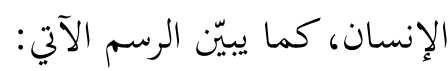

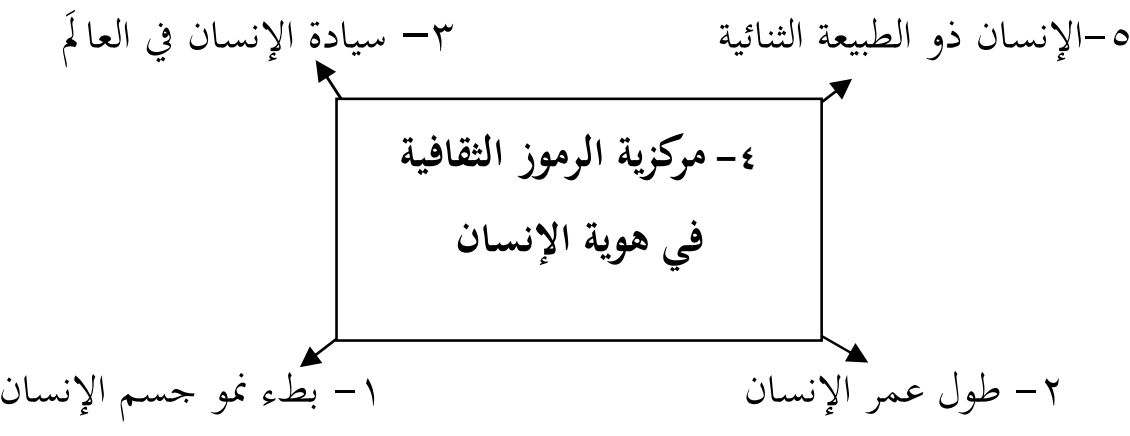

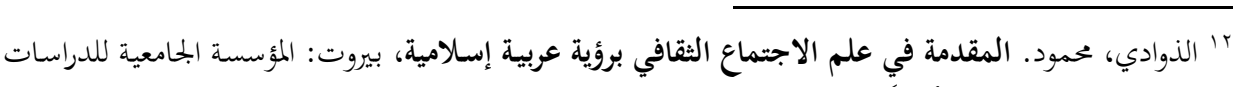

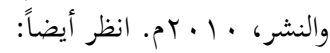
- الذوادي، محمود. الثقافة بين تأصيل الرؤية الإسلامية واغتراب منظور العلوم الاجتماعية، بيروت: دار 
إنّ المتأمّـل مركزية الرموز الثقافيـة في هويـة الإنسـان (آدم) قـد يطرح سؤالاً محوريّاً في

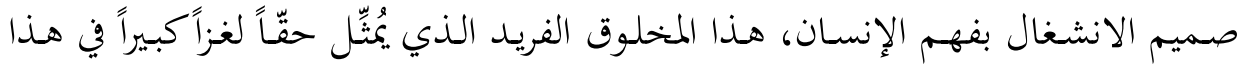

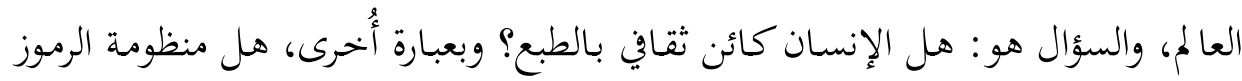
الثقافية مركزية في صُلْب هوية الإنسان؟ هول هُ الإسان

إنّ الإجابة الشـافية عن هذين السؤالين قد تتطلّب آلاف الكلمـات في مقـال، أو دراسة، أو كتاب، أو حتى العديد من البحلدات. ويمكن للمرء أن يتبنى -مثنلاً- منظور

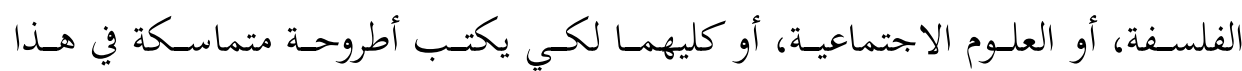

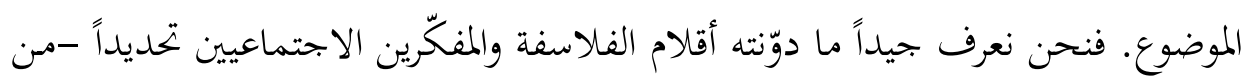

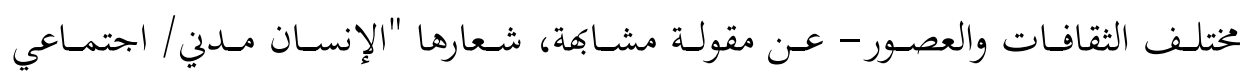

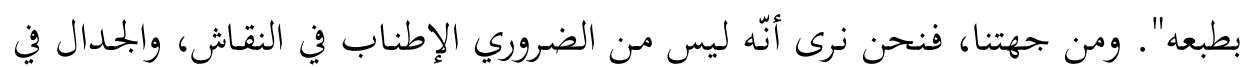
جوهر الحجج المؤكّدة للطبيعة الثقافية المميّزة للإنسان؛ إذ يمكن حسم المسألة في فقرات وسطور محدودة.

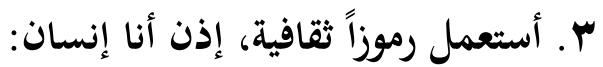

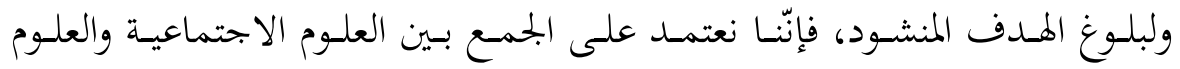
الطبيعية؛ إذ يصعب التعمّق في فهم طبيعة تميّز الإنسان مع غياب أيِّ من هذين الصنفين

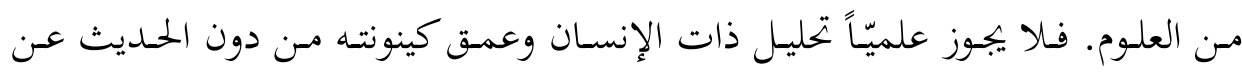
العوامل البيولوجية والفيزيولوجية (الجسمية) عند الإنسان. كما لا تُقبل محاولة فهم هذا لها

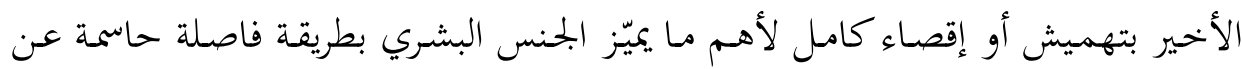

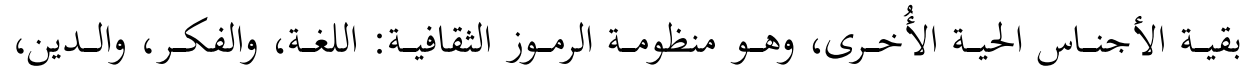

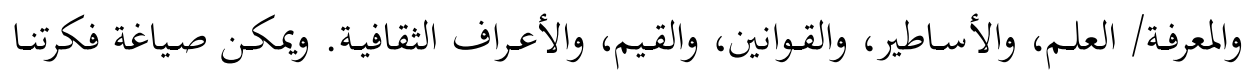

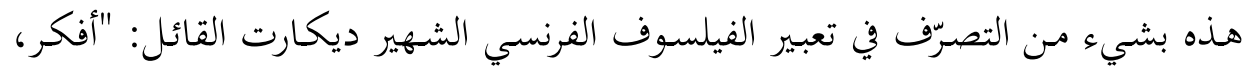
إذن أنا موجود"، ليصبح في مقولة طرحنا الفكري في هذا البحث: "أستعمل رموزاً ثقافية، 
ولإجحابة عن السؤال الآنف الذكر : هل الإنسان كائن ثقافي بالطبع؟ نقول: نعم، إنّ الإنسان هو حقّاً كائن ثقافي بطبعه قبل أن يكون اجتماعيّاً بالطبع.

يستند هذا القول إلى ملاحظات رئيسة حول خمسة معالم ينفرد بها الجنس البشري

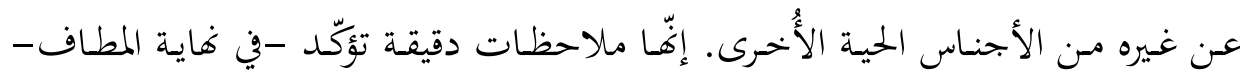

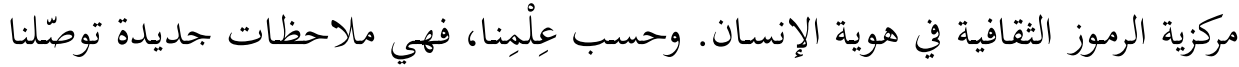

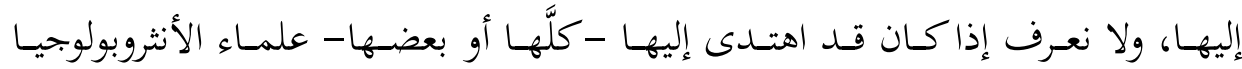

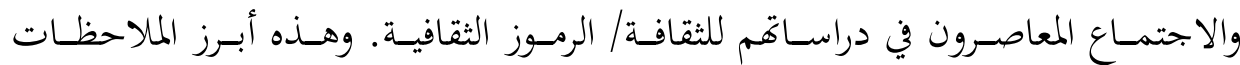
والتعليقات الخاصة بها:

1 . يتصف النمـو الجحسمي (البيولوجي الفيزيولوجي) لأفراد الجــس البشـري ببطء

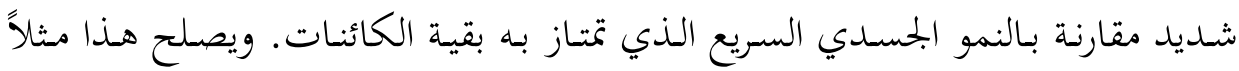

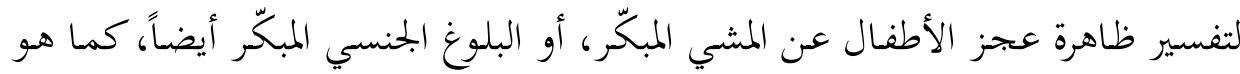
الحال عند صغار الحيوانات.

r . يتمتع أفراد الجنس البشري عموماً بأمد حياة (سِنّ) أطول من معظم الحيوانات.

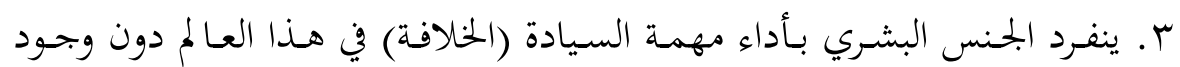

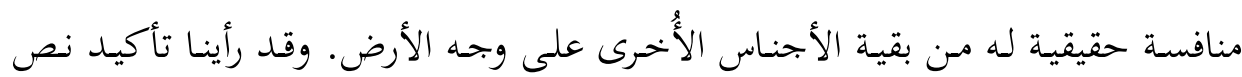
النقل في القرآن الكريم لتميّز آدم/ الإنسان وحده بمشروعية الخلافة؛ حتى على الملائكة أنفسهم.

ع ـ وكما ذ كرنا مـن قبل؛ يتميّز الجنس البشري بصورة فاصلة حاسمة عن الأجناس الأُخرى بما أطلقنا عليه اسم منظومة الرموز الثقافية.

ه. يختـص أفراد الجـنس البشـري بهويـة ثنائيسة (الجانـب الجسـدي، والجانـب الرمزي الثقافي). ويسمح هذا التصور الجمديد بتغيير التصور التقليدي لهوية الإنسان، المنادي بأنّ النّاب

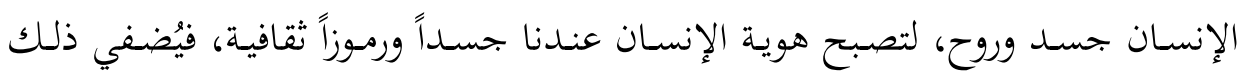


شفافية أكبر على فهـم السـلوكات البشرية الفرديـة والجماعيـة المتأثرة في العمـق بمنظومـة الرموز الثقافية ذات الصدارة المركزية في هوية الإنسان وتفسيرها.

والتساؤل المعريف المشروع الآن، هو: هل توجد علاقة تربط بين تلك المعالم الخمسة

التي يتميّز بها الإنسان؟

أ. هناك علاقة مباشرة بين المَعْلميْن: الأول، والثاني؛ فالنمو الجمسمي البطيء لأفراد

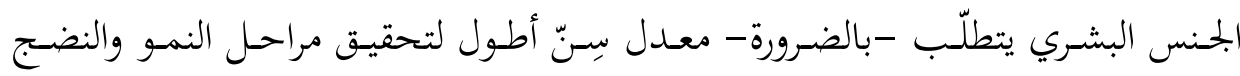
المختلفة المتعدّدة المستويات. فالعلاقة بين الاثنين هي -إذن- من نوع السببية. ب. إنّ الموية الثنائية التي يتصف بها الإنسان هي أيضاً ذات علاقة مباشرة بالعنصر الجسدي (المعْلم الأول) للإنسان، والعنصر الرمزي الثقافي (المعُلم الرابع). ت. عند البحث عن علاقة سيادة (خلافة) الجنس البشري بالمعالم الأربعة الأُخرى،

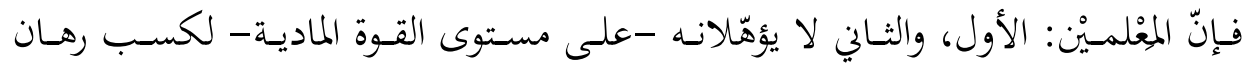
السيادة على بقية الأجناس الحية؛ فالإنسـان أضعف جسـديًاً من العديد من الكائنات

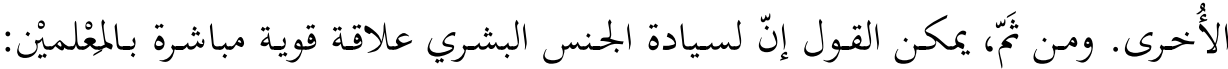

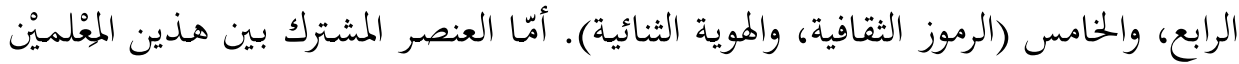
فهو منظومة الرموز الثقافية. وهكذا يتجلّلى الدور المركزي الحاسم لمنظومة الرموز الثقافية

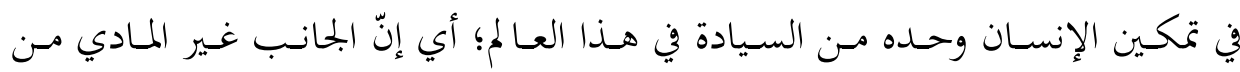

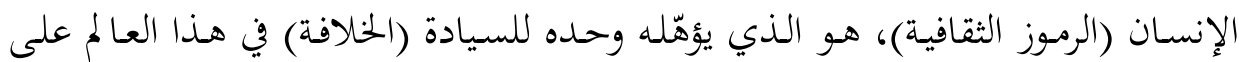
بقية الكائنات الأُخرى الفاقدة لذلك النوع من الرموز الثقافية التي يتميّز بها الإنسان. وعلى العموم، فـنحن لا نقول بالطريقـة التقليديـة التي ترى أنّ الرمـوز الثقافيـة غـير

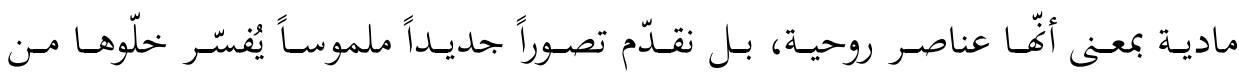

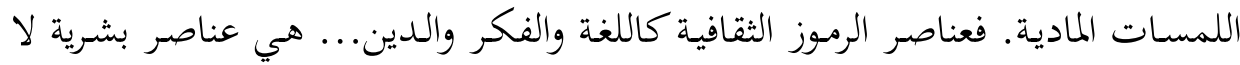

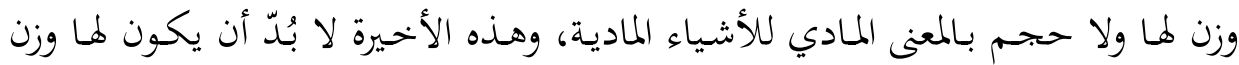
وحجم بصرف النظر عن صغرهما وضآلتهما. وهذا يعني -في فاية المطاف- أنّ الجانب 
غير المادي/ الرمزي الثقافي هو بيت القصيد في كينونة الإنسان، وهو ما تُلحّ على أهميته معظم المدارس الفلسفية البشرية عبر العصور، وكذلك الديانات، وفي طليعتها الإسلام. إنّ فقدان عالم الرموز الثقافية لعاملي الحجم والوزن يساعد أيضاً على تفسير سرعة

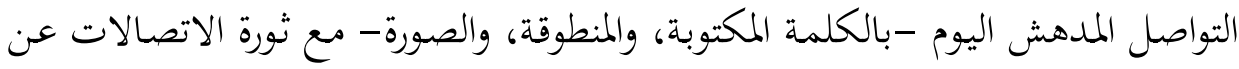

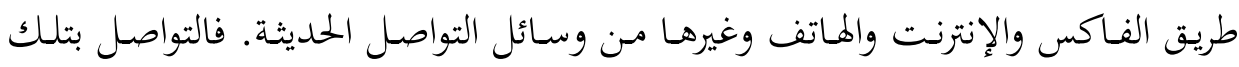

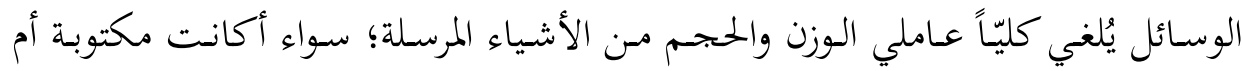

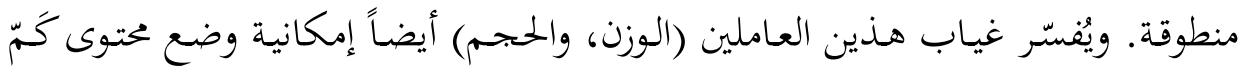

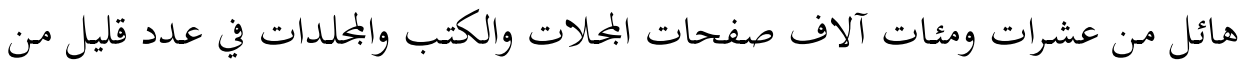
الحاويات الإلكترونية الصغيرة جدّاً (Flash Disks).

ث. إنّ الرموز الثقافية تسمح أيضـاً بتفسير المُّملميْن: الأول، والثاني. وهو أمر يبدو

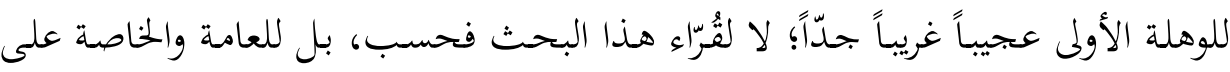
حدّ سواء، ونأمل أن يزول العجب والغرابة بعد فهم تفسيرنا لهذا الأمر . وكما يقال: "إذا لهاء

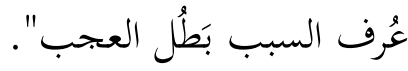
يُعزى النمـو البطليء لجحسم الإنسـان إلى اشتمال عمليـة النمو لديـه على جبهتين:

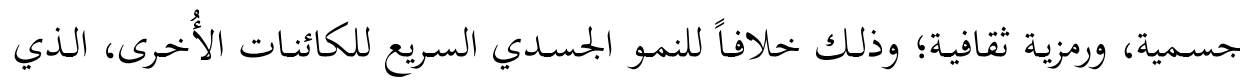

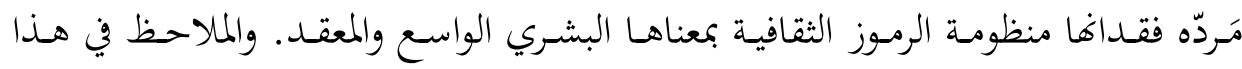

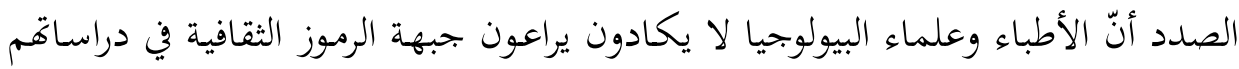

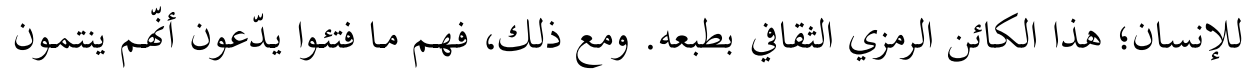

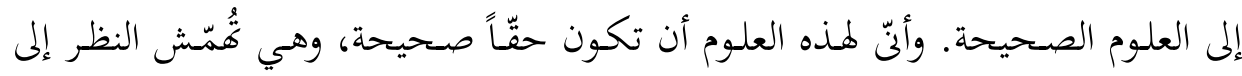
مركز هوية الإنسان (الرموز الثقافية)!

وتأسيساً على الأمثلة المتعلقة بمركزية الرموز الثقافية في هوية الإنسان، يمكن ابتكار

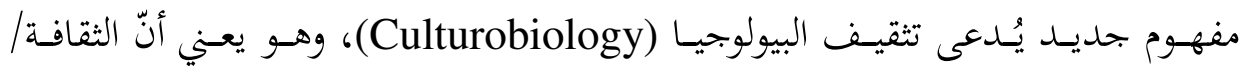
الرموز الثقافية تُؤثّر في بيولوجيا الإنسان. وعوداً على ذي ذي بَدٍِّ، يُّلخص الرسم المشار إليه

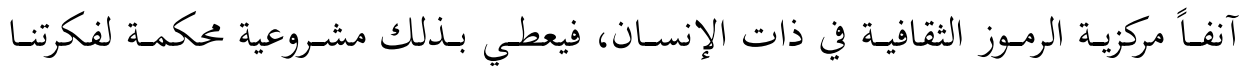




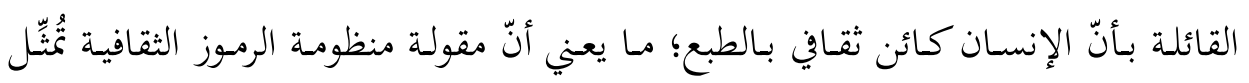

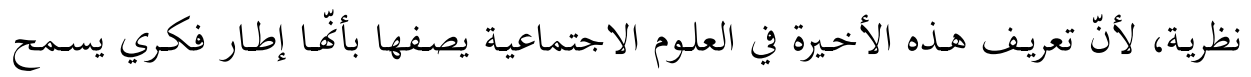

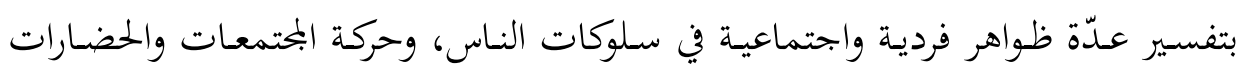

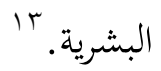

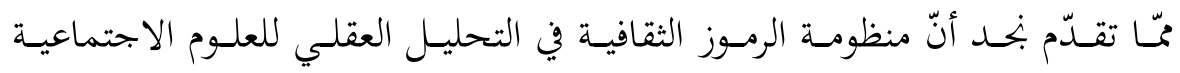

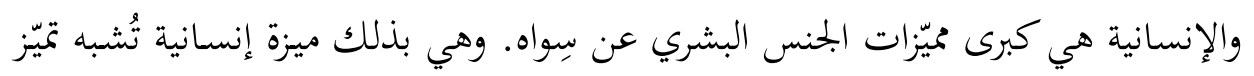

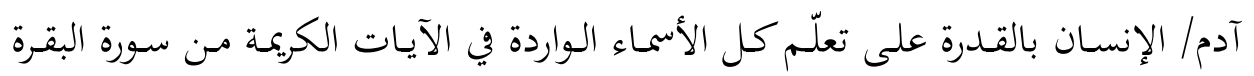

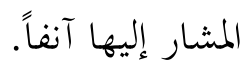

\section{ثالثاً: اللغة ونشأة الثقافة في المجتمع البشري}

بعد الشرح العقلي القائل بأنّ منظومة الرموز الثقافية هي خصيصة إنسانية بامتياز، مثلها مثل تميّز آدم بتعلّم الأسماء كلها كما ورد في النقل (القرآن الكريع)، يتعيَّن علينا الآن

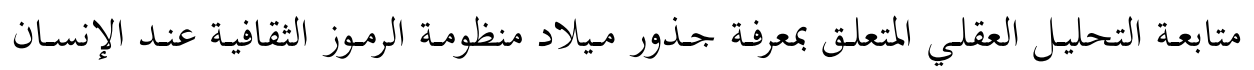

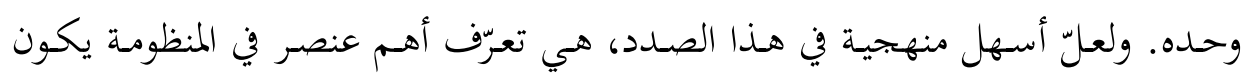

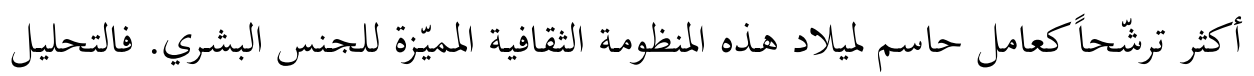

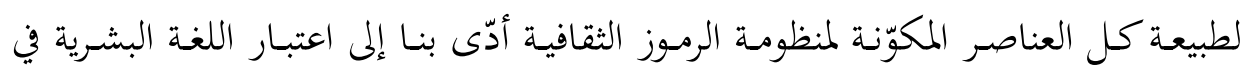

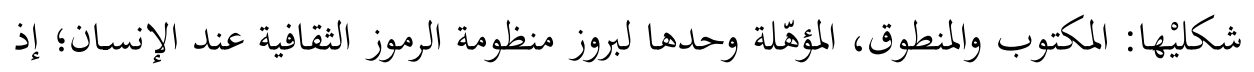

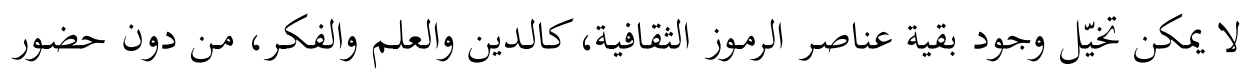

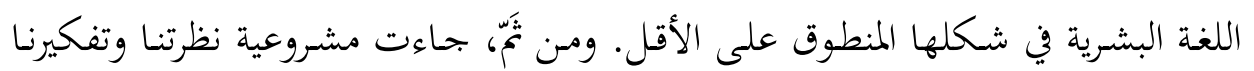
بأنّ اللغة هي أمّ الرموز الثقافية جميعاً.

ونظراً لمركية اللغة المنطوقة والمكتوبة في نشأة منظومة الرموز الثقافية؛ فإنّ وصف

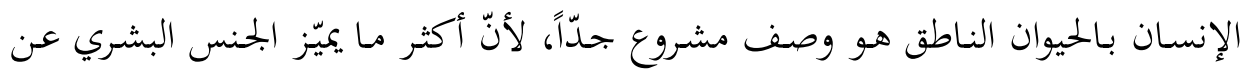

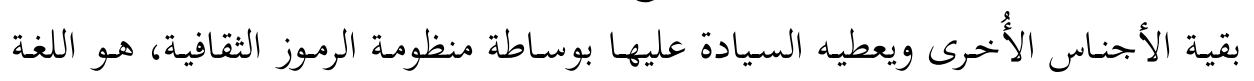
${ }^{13}$ Encyclopedia of Sociology, Guilford/USA, the Dushkin Publishing Group, Inc, 1974. 
المنطوقة والمكتوبة. وعلى الرغم من مركزية اللغة في هوية الإنسان، وما يتبعها مـن بروزٍ

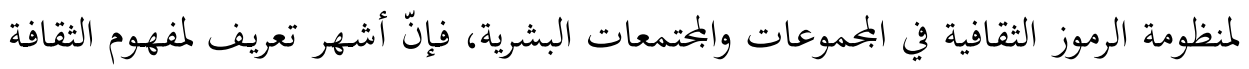

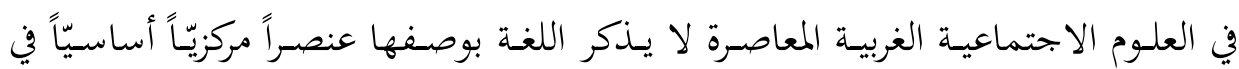

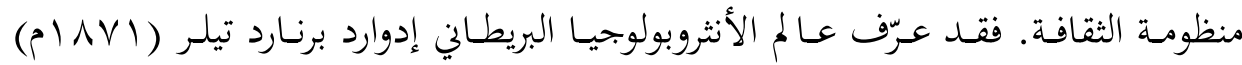

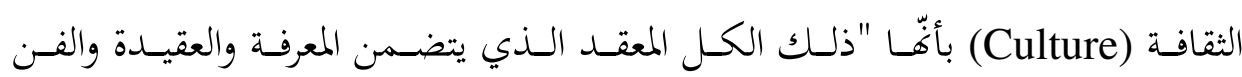
والأخلاق والتقليد، وأي مقدرات وعادات يكتسبها الإنسان كعضو في البحتمع." ويتمثّل قصور هذا التعريف الكلاسيكي للثقافة في إغفاله الإشارة إلى اللغة، وعدم

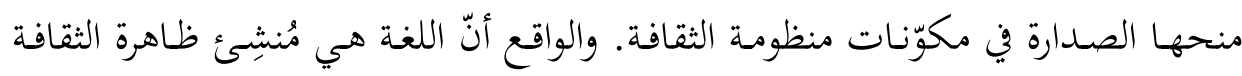

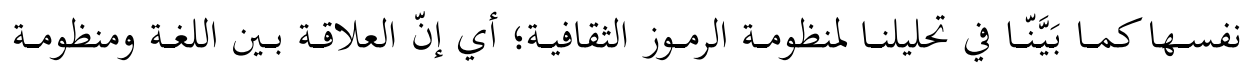

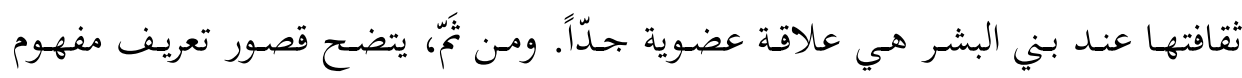

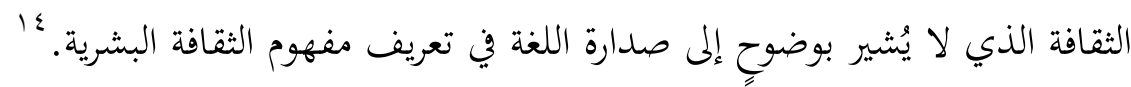
يتبيّن ممّا سبق أنّ نظريتنا للرموز الثقافية ترتكز على أنّ الثقافة هي ذلك الجانب غير

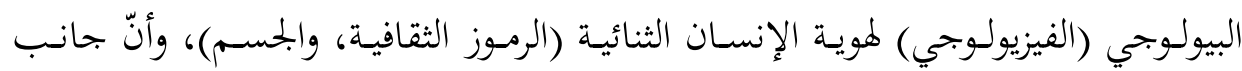

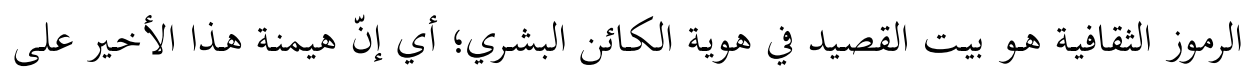

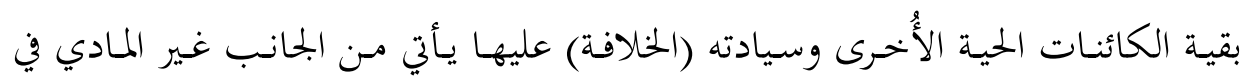

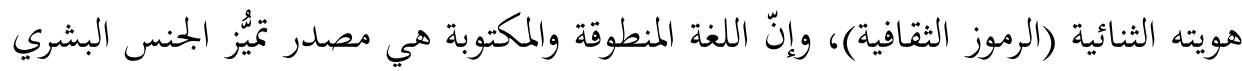

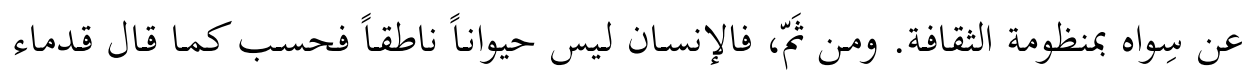

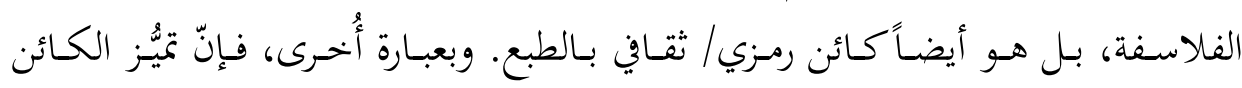

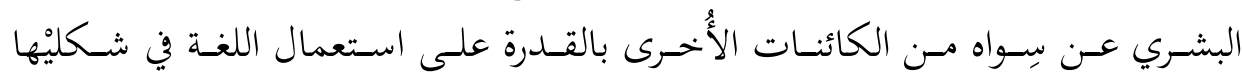

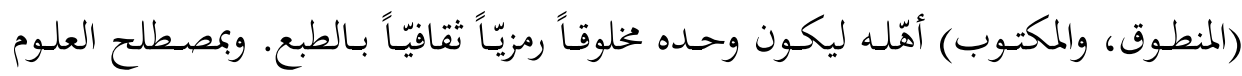

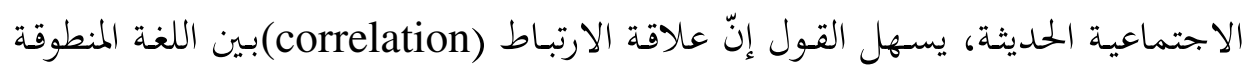
والمكتوبة عند بني البشر، وحضور ظاهرة الثقافة في المحتمعات الإنسانية؛ هي علاقة متينة إلباطية

${ }^{14}$ White, L. \& Dillingham, A. (1973) the Concept of Culture, Edina, MI: Burgess International Group. 


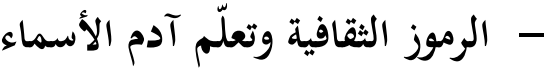

بعد البرهـان على خصوصية مركزية الرموز الثقافية في صُلْب هوية الإنسان، تُطرح

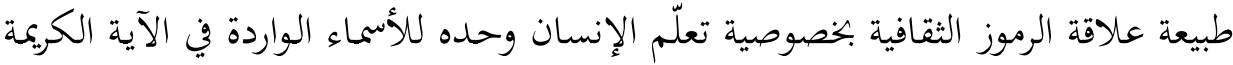

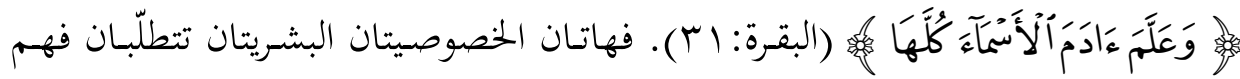

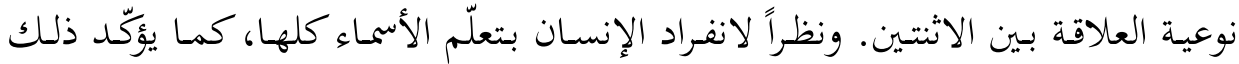

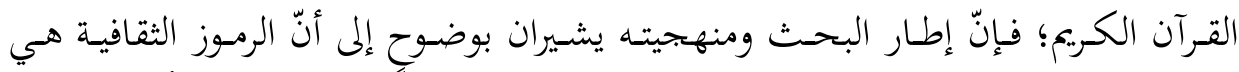

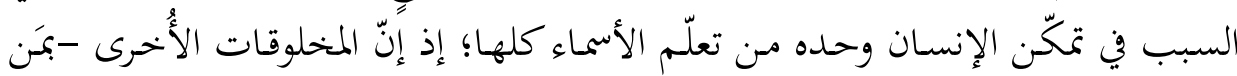

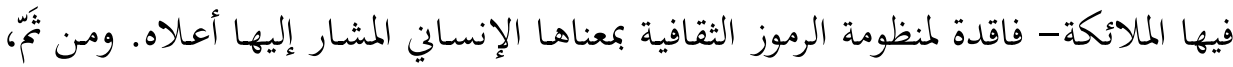

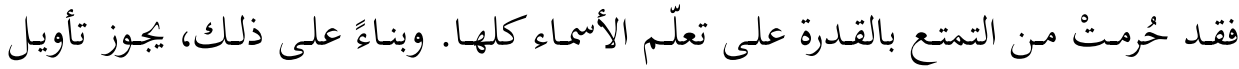

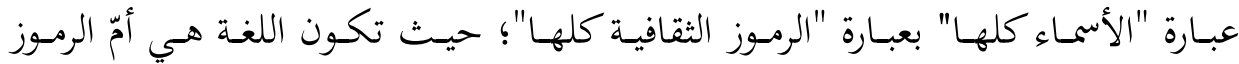

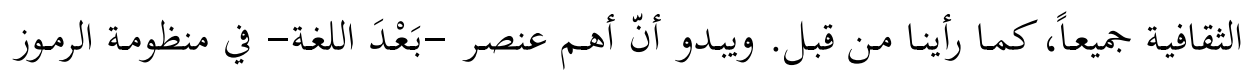

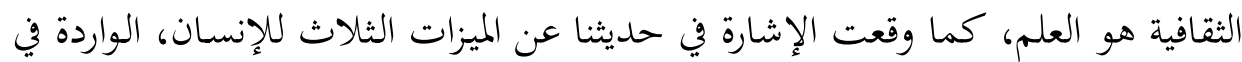

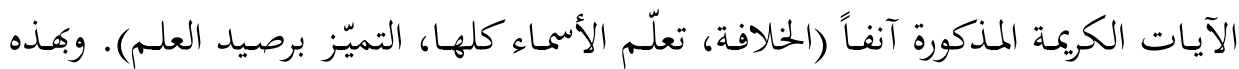

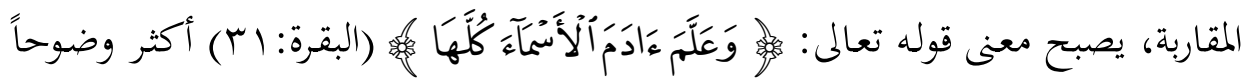
وشفافيةً مّّا رأيناه عند المفسترين والمفكرين المذكورين آنفاً.

\section{رابعاً: القرآن ومركزية الرموز الثقافية في الإنسان}

لا تستند مقولة "الإنسان كائن ثقافي بالطبع" في هـذا البحث إلى منهجية تحليل

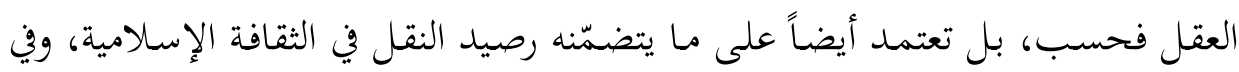

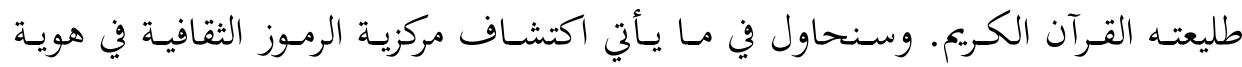
الإنسان من خلال الآيات التي ورد فيها ذكر "السمع" وكلمة "روحي" على التئل التوالي. 1 إلمارقات السمع والبصر عند الناس: من اللافت للنظر أنّ عامة الناس وخاصتهم في المجتمعات البشرية يَعُدّون البصر أهم

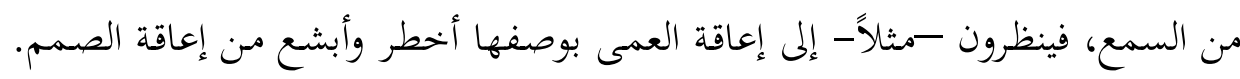


وهذا أمر جائز ؛ لأنّ العمى ظاهرة فيزيولوجية مادية تراها عيون المبصرين، خلافاً للصمم

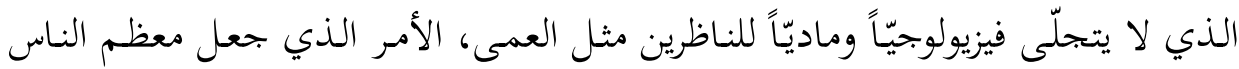
يميلون إلى عدِّ حاسة البصر أكثر أهمية وقيمة من حاسة السمع. وهي رؤية جماعية شعبية

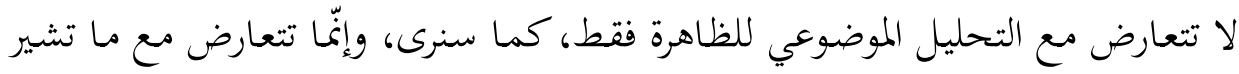

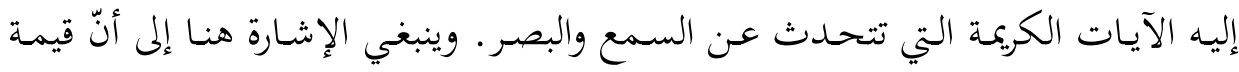

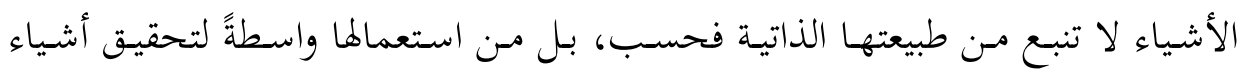

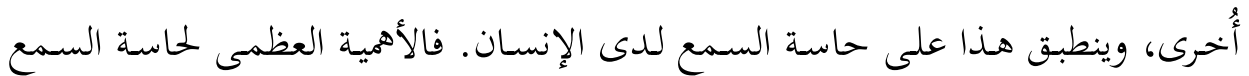

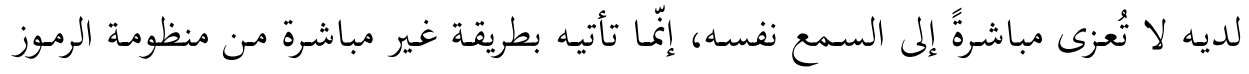

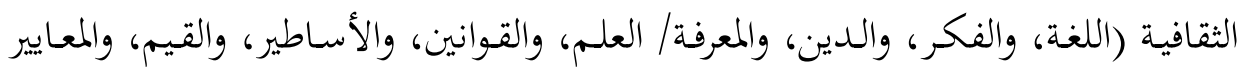
الثقافية) التي ينفرد بها الإنسان عن غيره من الكائنات، كما رأينا. ولو كان الأمر يرجع

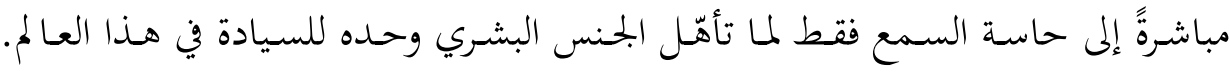
وعلى هذا، يمكن التعبير عن الهوية المميّزة للإنسان بالمعادلة الآتية:

$$
\text { الإنسان = الرموز الثقافية + السمع }
$$

فـلا تسـتطيع الاستعدادات والمؤهّلات الفطريـة للرمـوز الثقافيـة في الإنسـان أن ترى

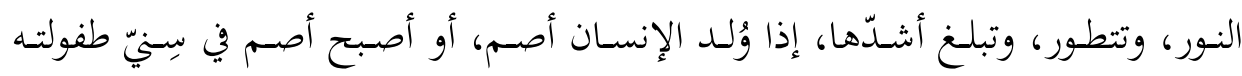

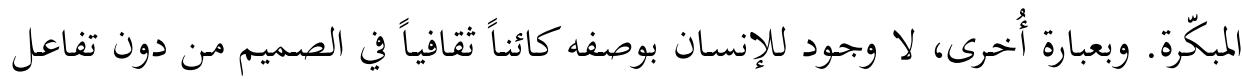

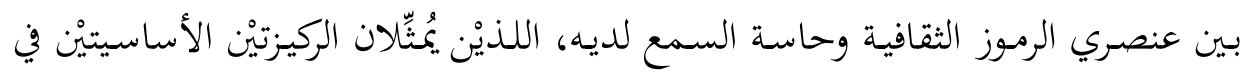
تكوين هويته الثقافية.

\section{Y ب العلاقة بين السمع والرموز الثقافية:}

أُتسيح لي اكتشــاف العلاقــة بــين حاســة السـمع والثقافـة لــدى الإنســان في

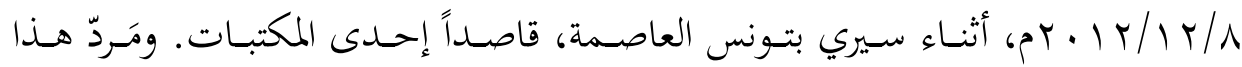

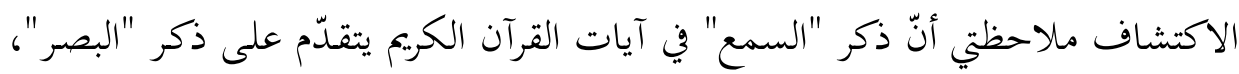

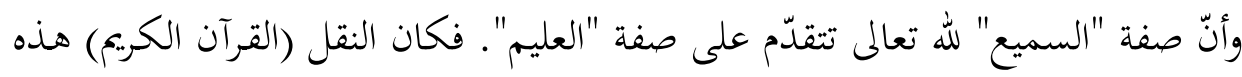


المرّة هو المصدر الأول الذي ألمني لكي أبحثث بوساطة العقل عن حكمة تقديم السمع

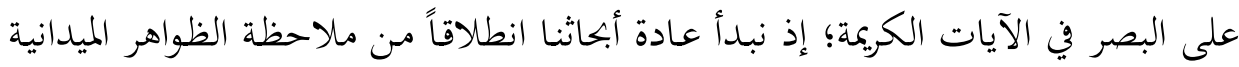

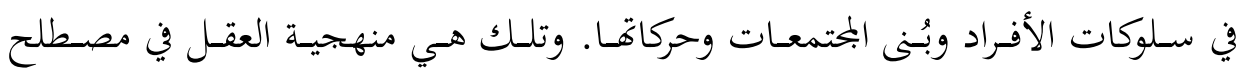
الثقافة الإسلامية. ومن تُمّه كان الجمع دائماً بين العقل والنقل في مسيرة دراساتنا وأبحاثنا

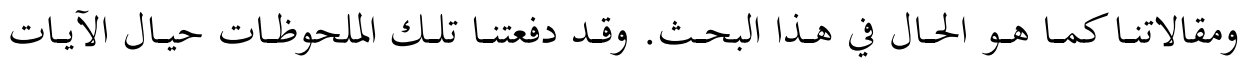

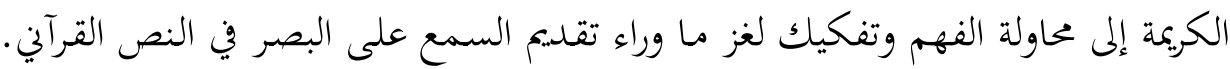

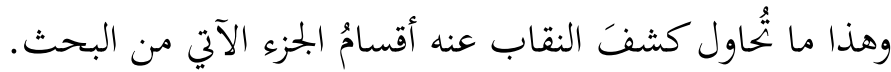
ب. تفوّق السمع على البصر في القرآن الكريم:

أحصينا أربع عشرة آية ذُكر فيها السمع دائماً قبل البصر عند الإنسان وفي أسماء الله

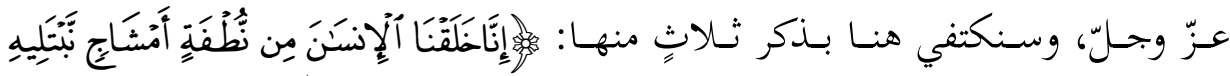

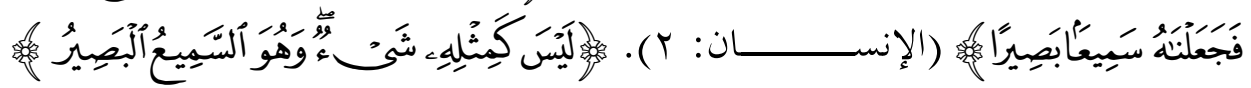

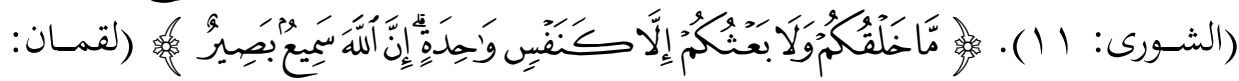
. (Y人

فتقـديم ذكر السـمع على البصـر أربع عشـرة مـرّة في تلـك الآيـات يـوحى بـأنّ هـذا

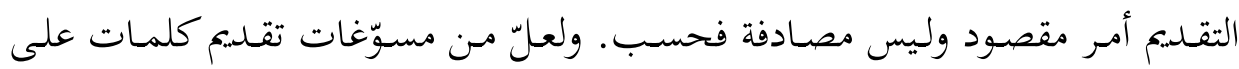

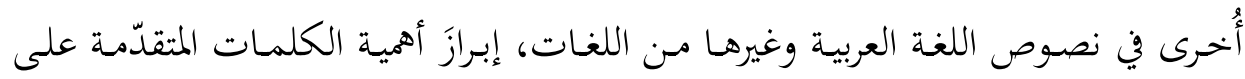

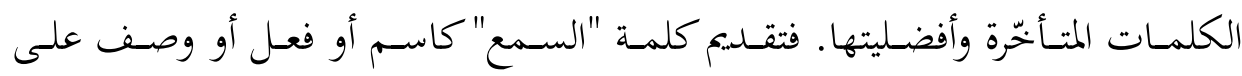

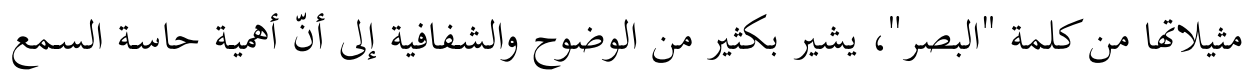
تفوق كثيراً حاسة البصر.

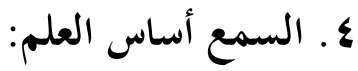

حَفَاَـتْنْ ثلاتـون آيـة مـن القـرآن الكـريم بكلمـة "السـميع" التي تسـبق دائمـاً كلمـة

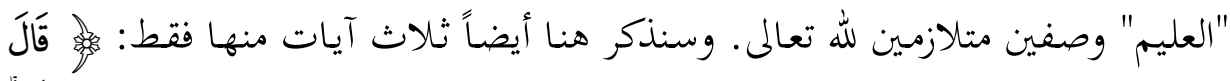

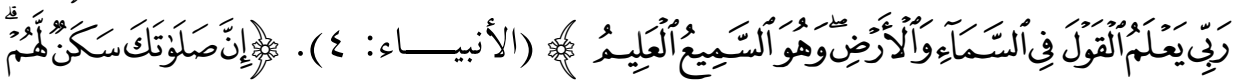




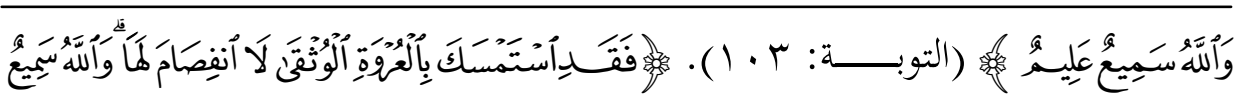

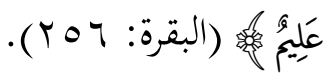

فتكرار صفة "عليم" بعد صفة "سميع" توحي بأنّ العلم يعتمد دائماً على السمع. ومن تَّهّ، فالعلاقة بين السمع والعلم هي علاقة سببية. إنّ الصـدارة التي تتمتع بهـا كلمـة "سميع" أمـام كلمتي "بصير" و "عليم" في الآيـات

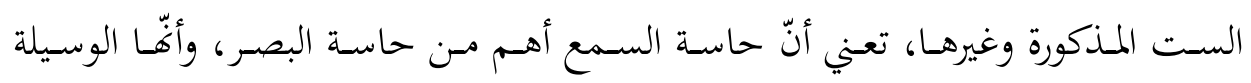

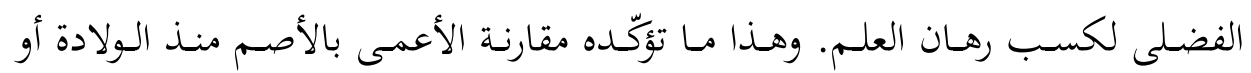

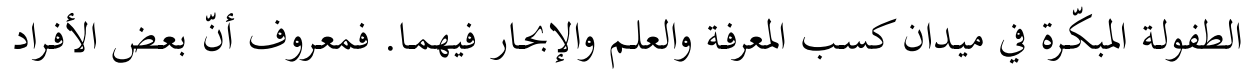

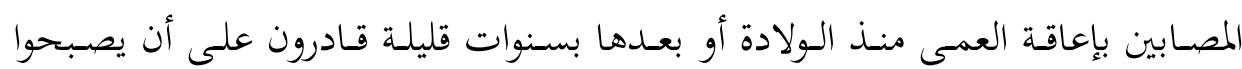

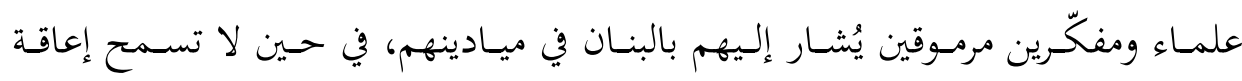

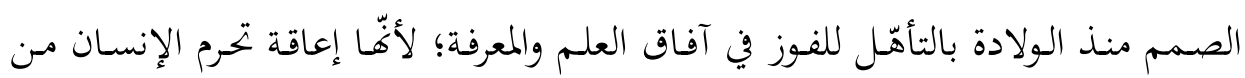

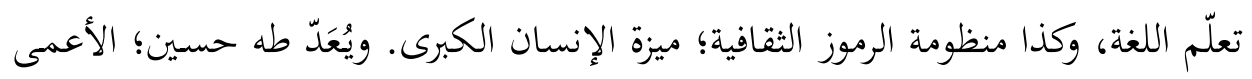

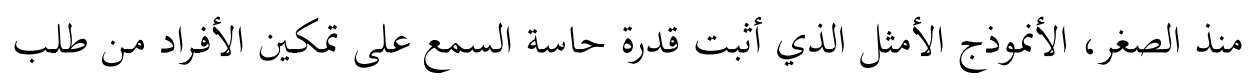

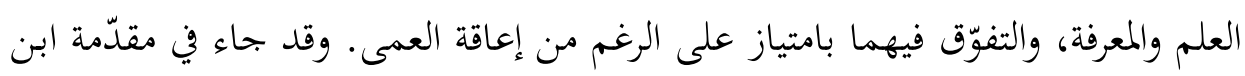

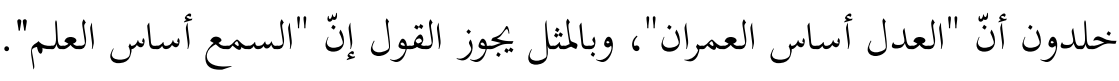

\section{هـ السمع منبع ثقافة الإنسان:}

تكمن الأهمية الكبرى لحاسة السمع في كوفا سبيلاً لتحقيق طبيعة الإنسان الثقافية،

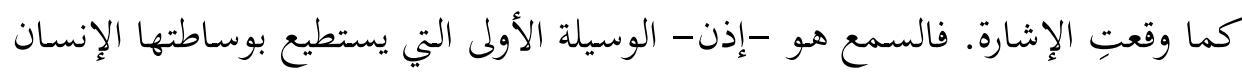

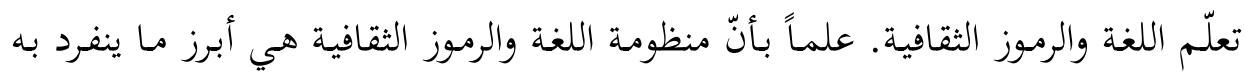

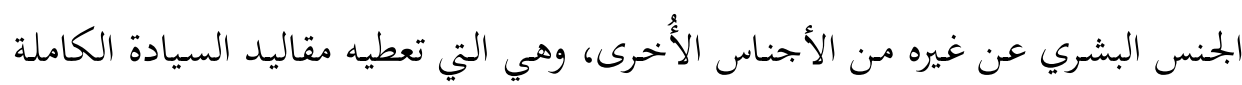

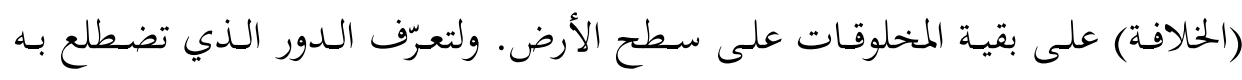

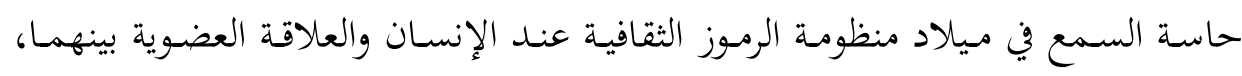




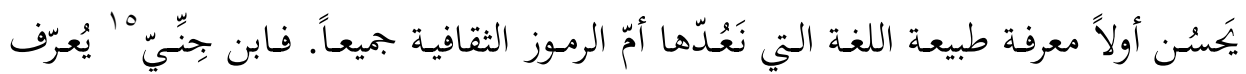

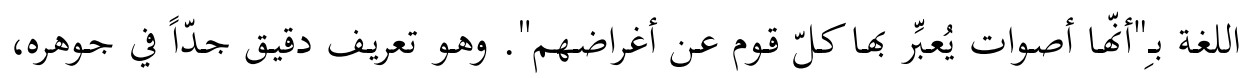
ومتناسق كثيراً مع تعريفات الباحثين المعاصرين للغة.

وفي الوقت الذي يؤكّد فيه ابن جِنِّيّ وعلماء اللغة المحدثون جانب الطبيعة الصوتية

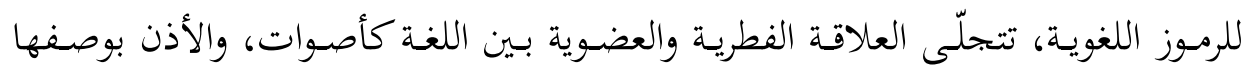

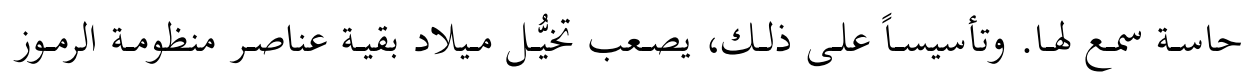
الثقافية، كالفكر والدين والعلم والقيم، مع الغياب الكامل للغة كأصوات بشرية؛ أي إنّ دهاب

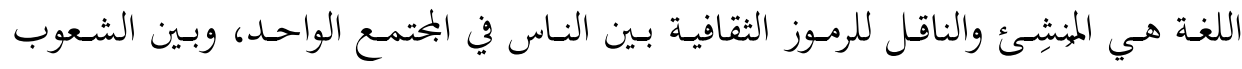
والأمه، وبين الحضارات الإنسانية جمعاء.

\section{צ. الصمت عن الوظيفة الكبرى للسمع:}

لا يكاد معظم المفسّرين للقـرآن الكريم يـذكرون شيئاً عن الحكمة مـن تقديم كلمـة

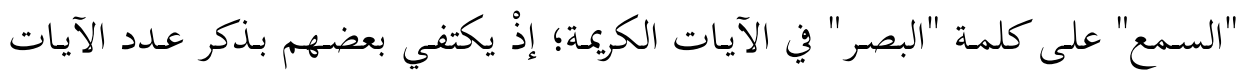

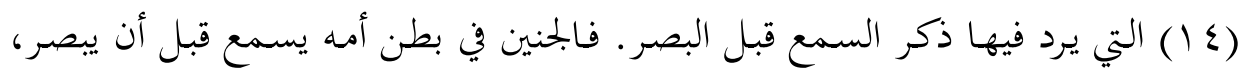

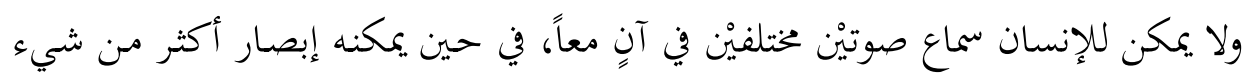
بـالعين الواحـدة. وبـذا، يمكـن فهـم الحكمـة مـن إيـراد السـمع بـالإفراد، وإيـراد الإبصـار

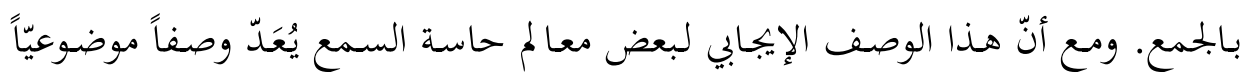

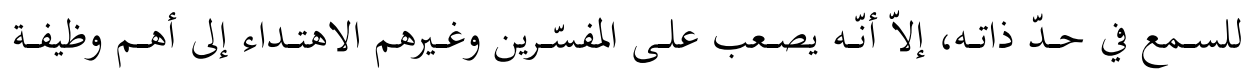

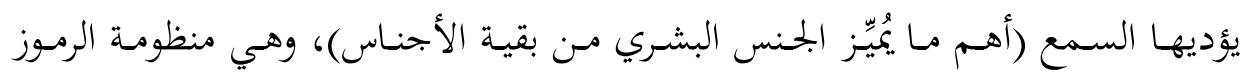
الثقافية.

يُفترض أنّ لمؤلاء جميعاً إدراكاً مـا بوجـود الرموز الثقافية عند الإنسـان، ولكنّ هـذا الإدراك (العادي البسيط) لا يكفي لتفسير سبب تفضيل السمع على البصر في الآيات

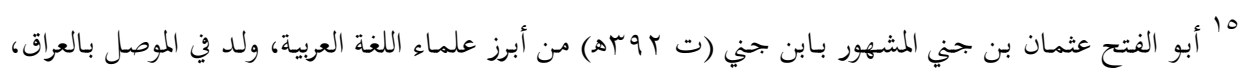

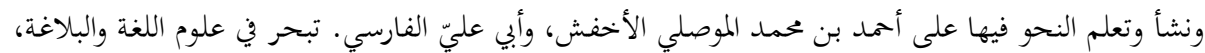

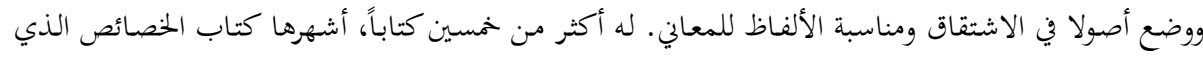


الكريمة. ففهم ما وراء أفضلية السمع يحتاج إلى إدراك معريف (إبستمولوجي) عميق بالنسبة

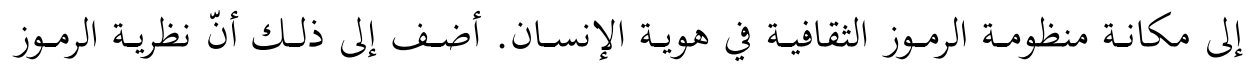

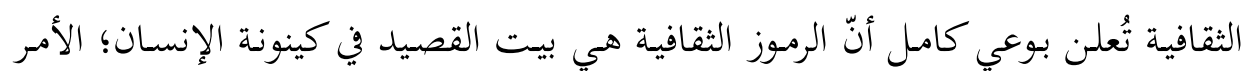

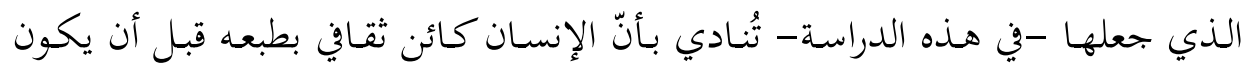

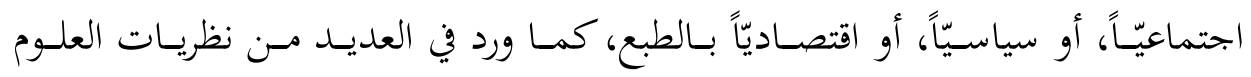
الاجتماعية والإنسانية الحمديثة.

إنّ مقولة هذه النظرية تُعطي مشروعية واضحة وصريحة لتفضيل السمع على البصر. فالسمع -وليس البصر - هو الأساس الضروري لتعلّم اللغة، ونشأة منظومة الرموز الثقافية عند الإنسان؛ أي إنّ حاسة السمع هي الملكة المسؤولة عن نشأة منظومة الرموز الثقافية، وحمايتها، وتطويرها، واكتمالها عند بني البشر كافة.

وقد يتوارد إلى روع القارئ سؤال مفاده: ألا تُؤهّل هذه الوظيفة السامية السمع لنيل تأشيرة الأفضلية على البصر وغيره مـ حواس الإنسـان الأُخرى كما تُشير آيات القرآن

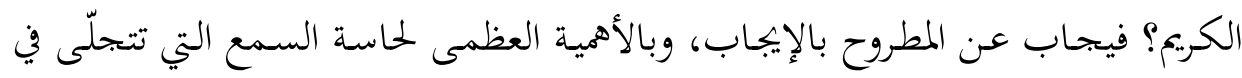

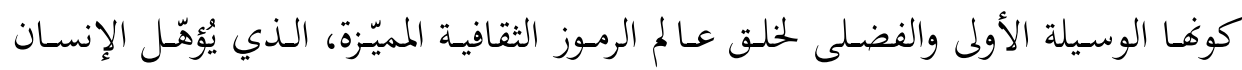
وحده ليكون سيد هذا العالم بسبب تمكين الرموز الثقافية له من تعلّم الأسماء كلها. يتضح مُّا سبق، ومن أطروحة النظرية، أنّ هوية الإنسان هي هوية رمزية ثقافية في الصميم، يتميّز بها عن غيره من الكائنات بسبب تمتعه بكلٍٍ من حاسة السمع، ومنظومة فئة

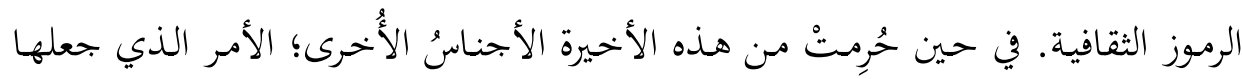
عاجزة -رغم تمتعها بالسمع - عن إنشاء منظومات ثقافية مشابهة لمنظومة الرموز الثقافية لـدى الإنسـان. وعلى هـذا، فبإنّ زمالـة السـمع والرمـوز الثقافيـة همـا شـرطان أساسـيان ومؤسسـان لظهور الإنسـان ككائن متميّز وقادر وحـده على السيادة (الخلافـة) في هـذا

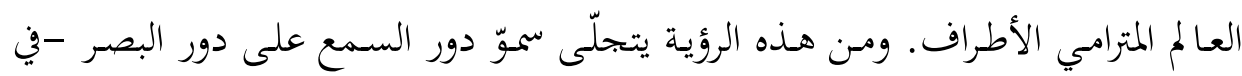

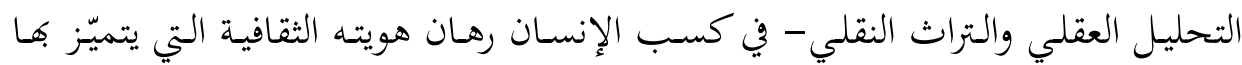


على بقية المخلوقات على وجه الأرض ويعلو بها عليهم. وهكذا، يتضح جليّاً أنّ ثنائية

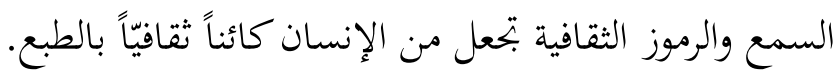

إنّا نظرية تختلف -معرفيّاً وفكريّاً- عن نظريات الماركسية والبنيوية والتحليل النفسي، وعـن رؤى مـدارس العلـوم الاجتماعيـة والإنسـانية الحلديثـة التي لم تطـرح منظومـة الرمـوز

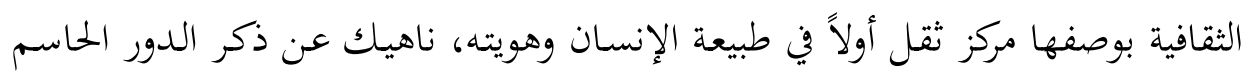
لحاسة السمع في ميلاد منظومة الرموز الثقافية لدى الجنس البشري فقط، كما سبق بيانُه

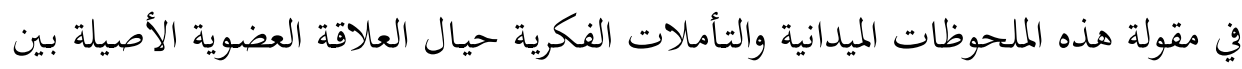

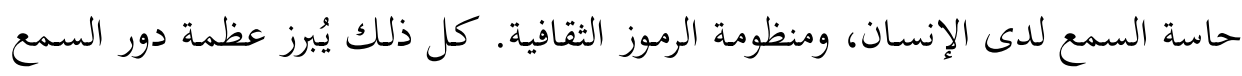

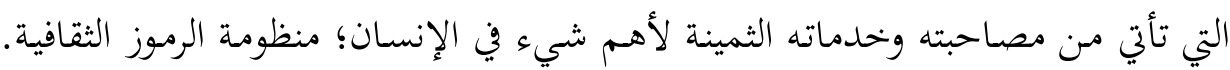

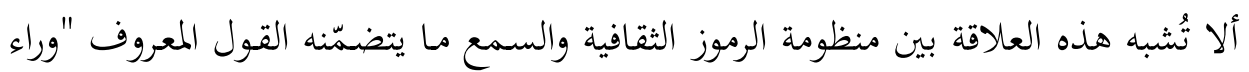

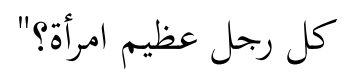

\section{V. التأويل الثقافي لكلمة "روحي" في القرآن الكريم:}

إنّ التأويل العميق والبـديل لبعض الآيـات الكريمـة مـن النص القـرآني سيُفضي -في

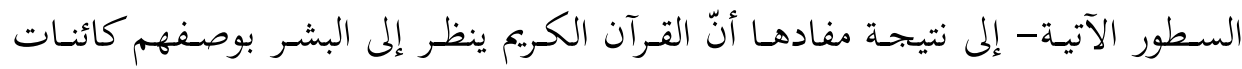

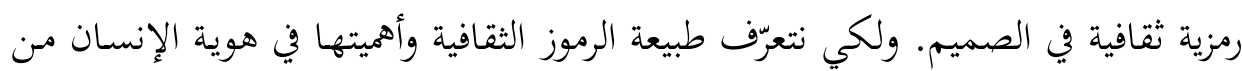

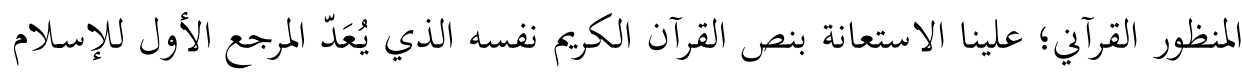
في شتيّ المناحي والميادين.

وتأسيساً على ذلك، فنحن نقدّم هنا الرؤية المعرفية القرآنية لطبيعة الرموز الثقافية.

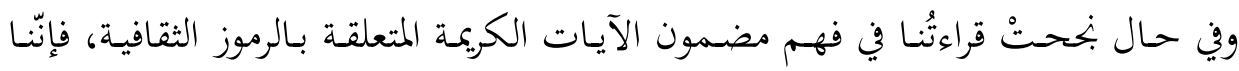
نكون قد كسبنا الرؤية المعرفية الإسلامية الصحيحة عن طبيعة الثقافة. فضالاً عن تسليح

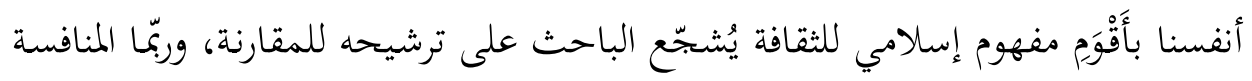

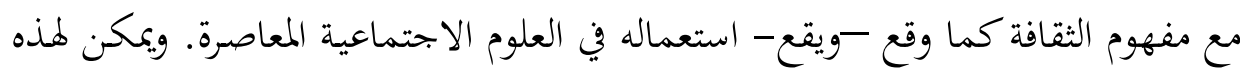

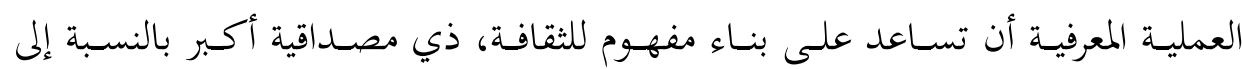

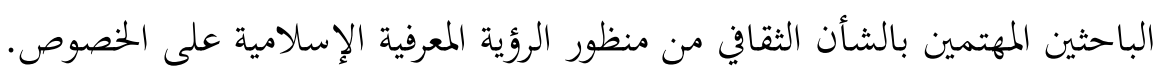


وفي حـال وجـــنا أنّ الرؤيسة القرآنيـة للرمـوز الثقافيـة تتشـابه أو تتطـابق مـع تحليلنـا

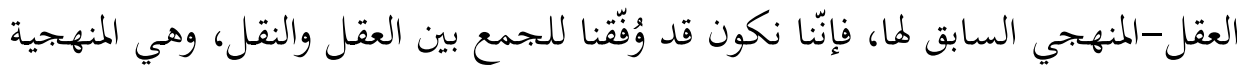

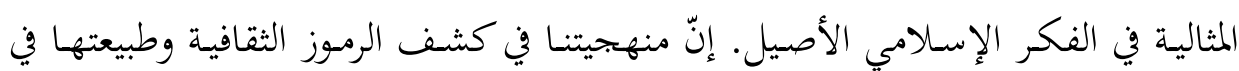

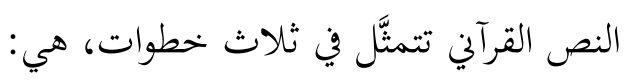
- هل توجد إشارات واضحة في القرآن الكريم تُميّز الإنسان عن غيره في خلافة الله

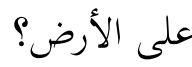
- هل توجد آيات قرآنية تتحدث بصراحة مطلقة عن تميّز الجنس البشري عن بقية

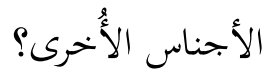

- إلى أي شيء تعزو الآيات الكريمة تميّز الجنس البشري وتفوّقه؟ بدايـةً، يجفـل النص القرآين بالعديـد مـن الآيـات الكريمـة التي تخص الإنسـان بمكانة

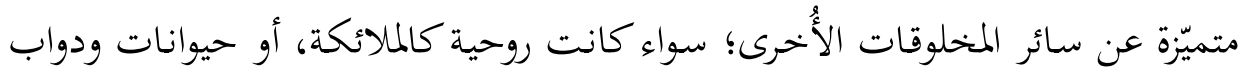

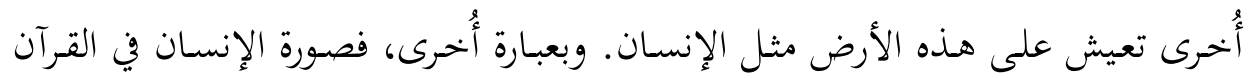

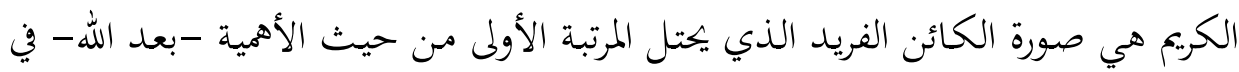

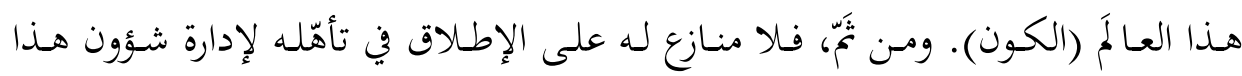

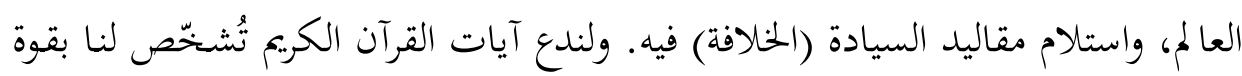

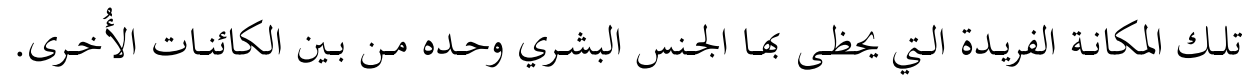

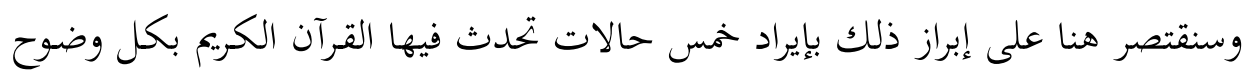

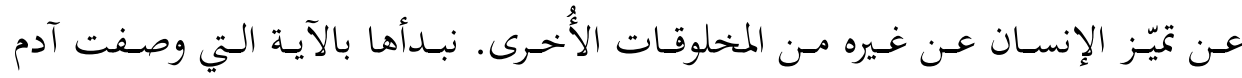

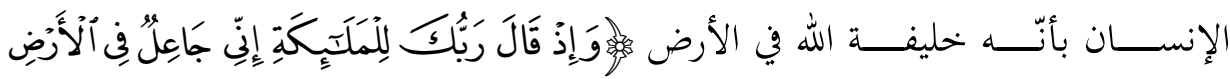

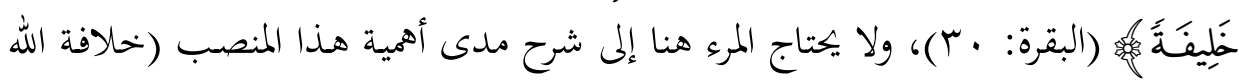

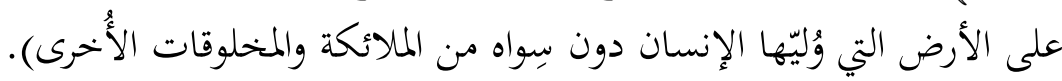

أمّا ميّزات الإنسان المطلقة التي تحدثت عنها الآيات الثلاث بعد تلك الآية مباشرة السورة، فهي تتمثَّل في اصطفاء الله لآدم بالمعرفة والعلم أكثر من المخلوقات الأُخرى، بمَن

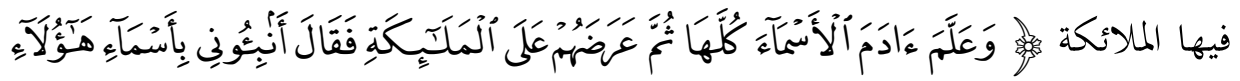




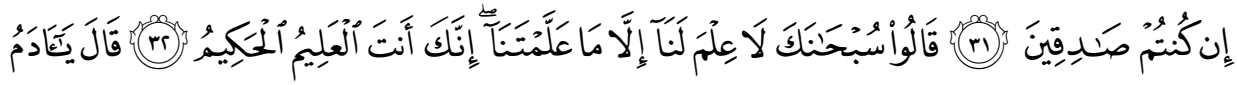

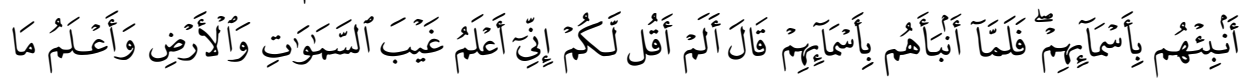

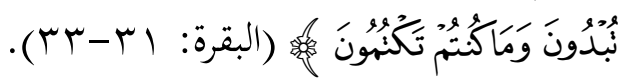

ونتيجة للميزتين السابقتين اللتينْ لم تنلهما الملائكة وبقية الكائنات، وتفرّد بكما

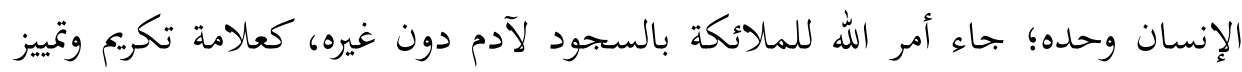

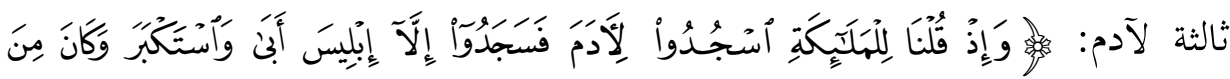

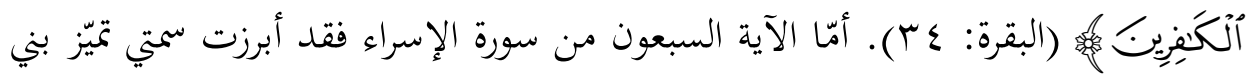

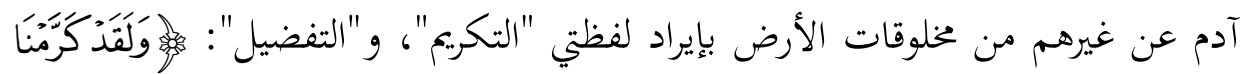

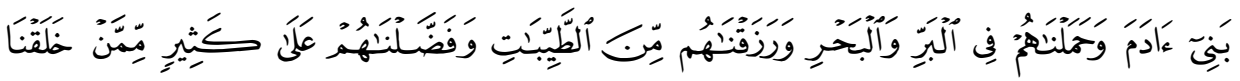

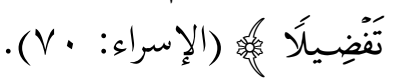

فهذه الآيات الكريمة تُوضّح بما لا يدع بحالاً للشك أنّ الإنسان كائن خاص متميّز

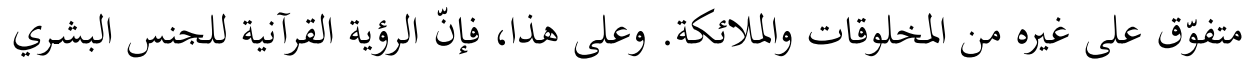

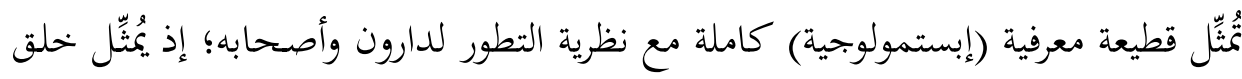

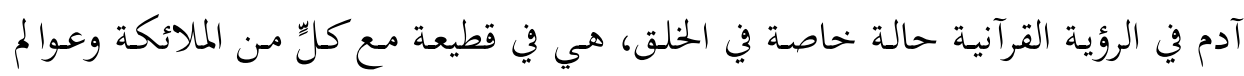

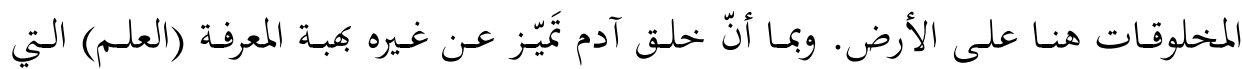

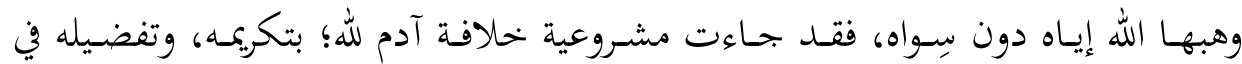

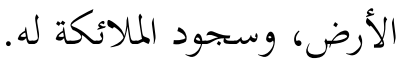

ومّمّا يُلفت الانتباه وجود آيتين كريمتين تربطان سجود الملائكة لآدم بنفخ روح الله

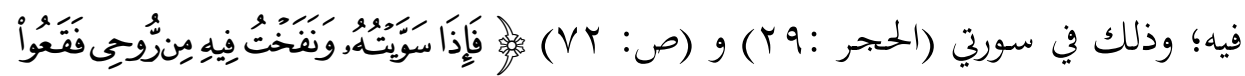

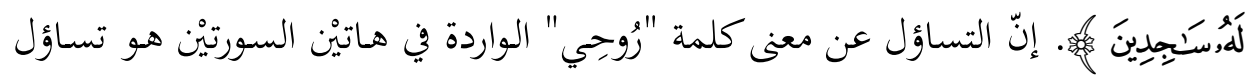

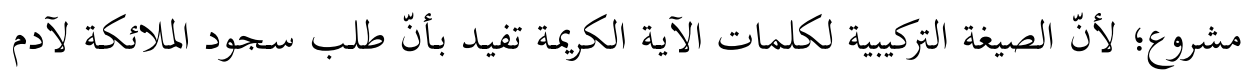

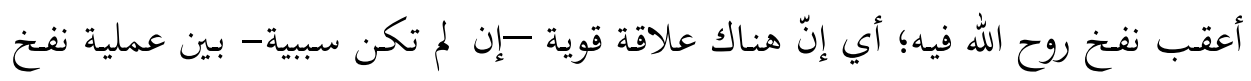

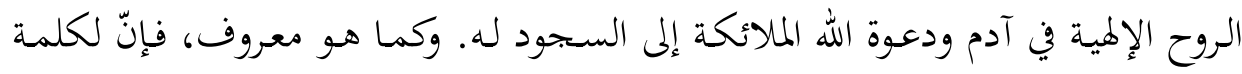

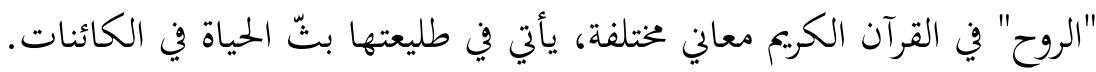




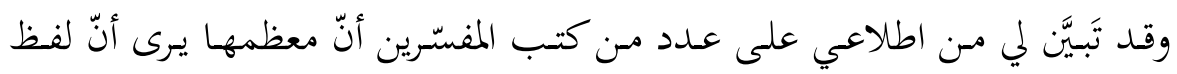

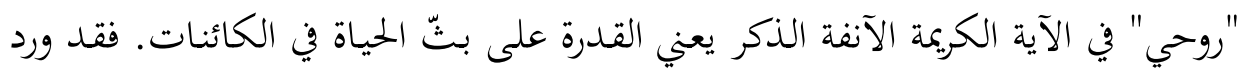

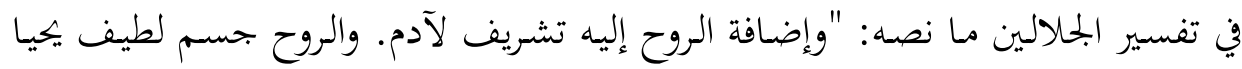

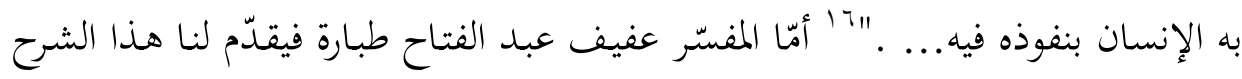

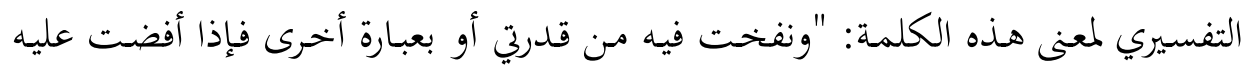

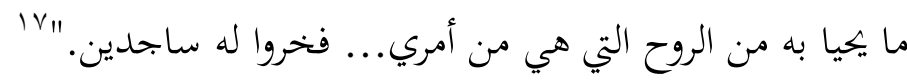

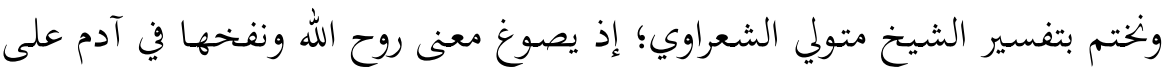

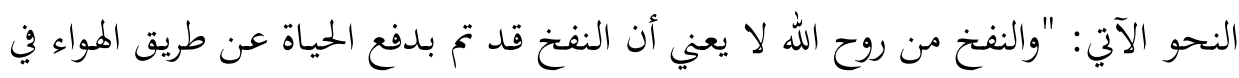

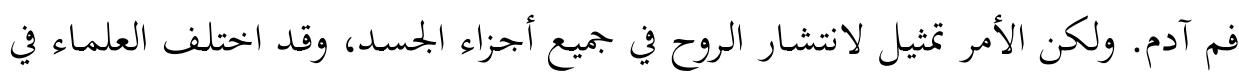

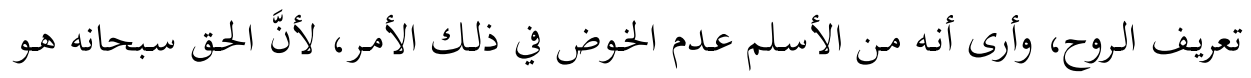

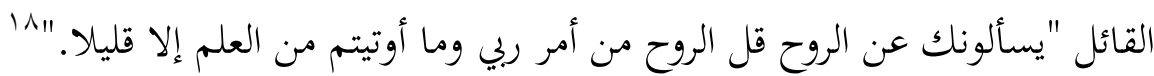
فواضح من مضمون هذه التفاسير أنّ معنى لفظ "روحي" اقتصر على معنى قدرة الله آله

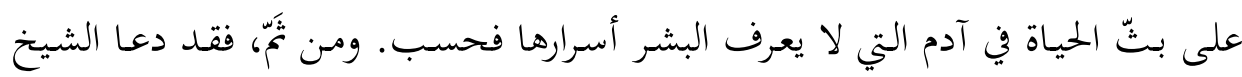
الشعراوي إلى تحاشي الخوض فيها.

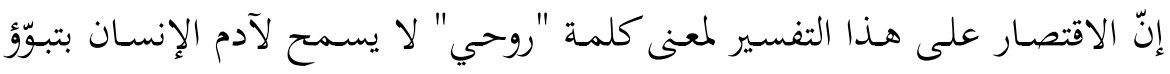

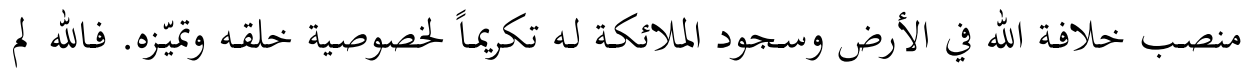

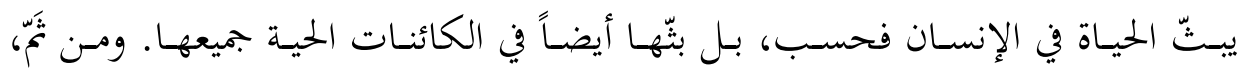

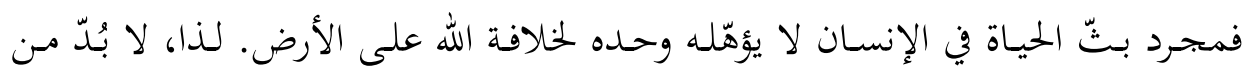

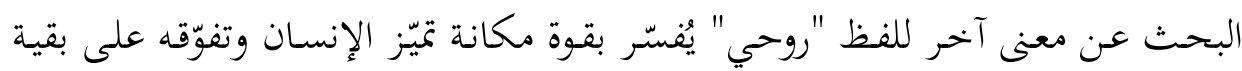
المخلوقات في إدارة شؤون الأرض بوصفه خحليفة لله.

وهنا يأتي - في رأينا- دور العلوم الاجتماعية في مساعدة مفسّري القرآن الكريم،

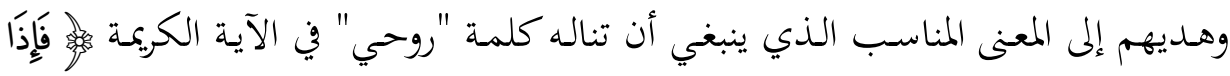

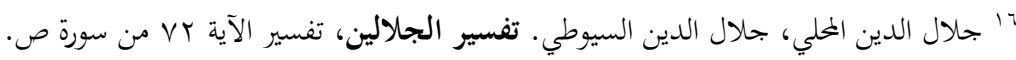

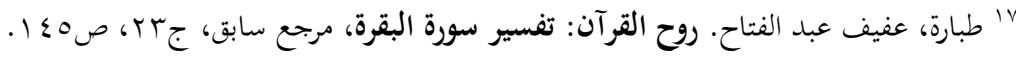

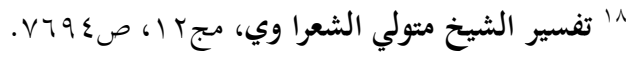




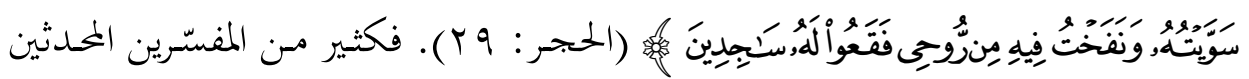

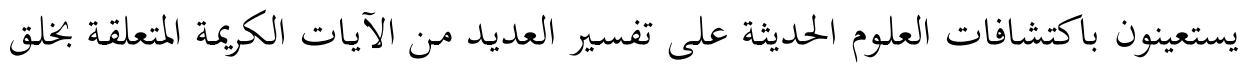

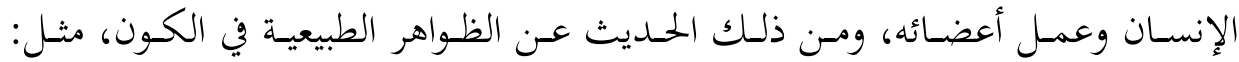

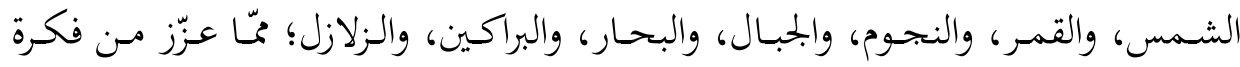

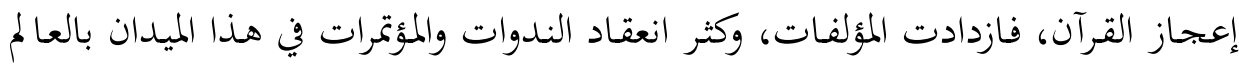

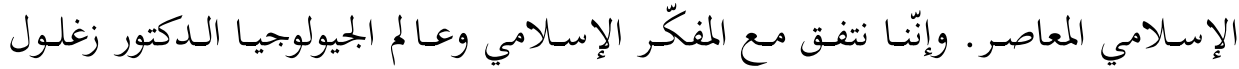

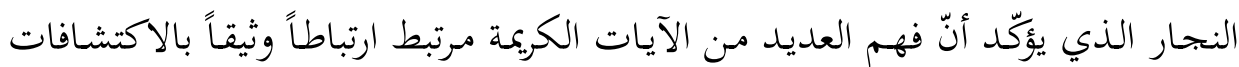
العلمية ذات الصلة بالإنسان والظواهر الطبيعية للعالم (الكون). والمفسّرون المحدثون مطالبون هم أيضاً، وبالدرجة نفسها، بالإفادة من الرصيد المعرفي

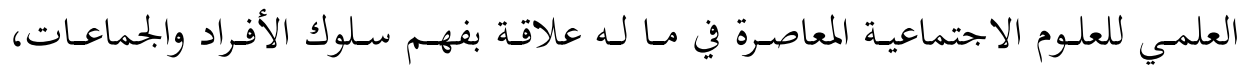
وحركة المجتمعات، والمعالم الثقافية البشرية. فهذه العلوم تساعد -ولا شكُّ- على استكناه معنى كلمة "روحي" في الآية الكريمة المشار إليها أعلاه.

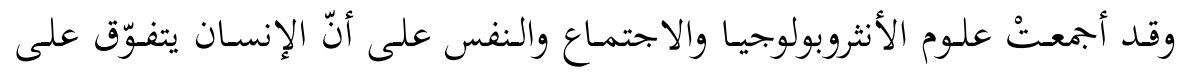

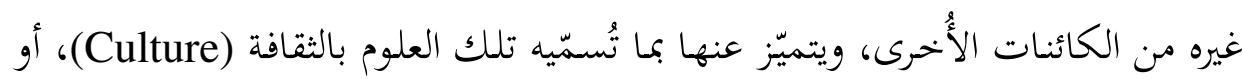
ما أطلقنا عليه نحن في هذا البحث اسم "الرموز الثقافية" (اللغة، الفكر، الدين، المعرفة/

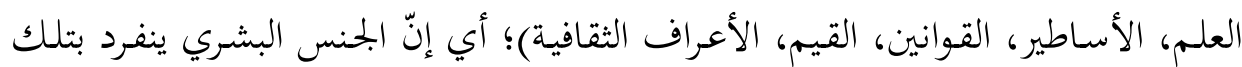

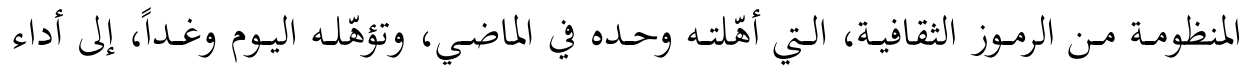

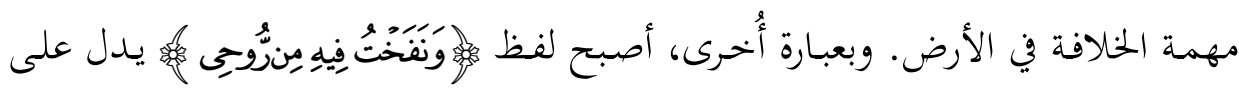

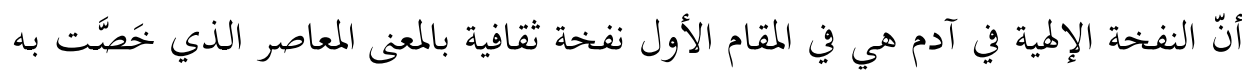

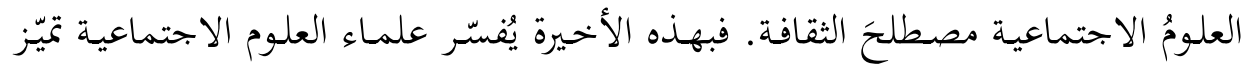

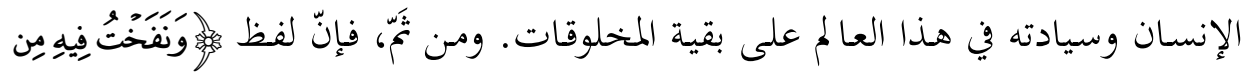

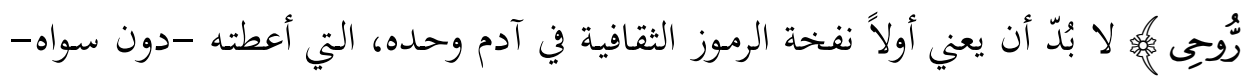
مقاليد الخلافة في الأرض، وما تبعها من سجود الملائكة له. فبهذه القراءة الثقافية لمعنى آلماني كلمة "روحي" في الآية الكريمة يتضح لنا مدى تحسّن مصداقية تفسير معاني آيات القرآن 
الكريم؛ لـو استعان المفسّرون بالرصيد العلمي الحـديث لكـلِّ مـن علوم الطبيعـة وعلوم الإنسان والمحتمع على حدّ سواء.

وكمـا ذكرنـا، فبإنّ مـا أوردته كتـب المفسّرين لمعنى "النفخـة الروحيـة الإلهية" في الآيـة الكريمة يبقى غامضاً؛ الأمر الذي يتطلّب ابتكار منهجية جديدة تتجاوز مبادئ المنهج الوضعي، وتعمل على تحريرنا من استعمال رموز غير محددة لا تُفضي إلى فهم قريب أو أكثر واقعية لطبيعة النفخة الروحية الإلهية التي يتحدث عنها القرآن الكريم. ومن أجل استجاء الغموض الذي يحيط بطبيعة النفخة الروحية الإلهية، ارتأينا تبنّي المنهجية الآتية: - n

ا ـ انتهاج طريقـة موضـوعية -بمؤشـرات محسوسـة- لتعرُّف العناصر التي يتميّز بهـا الجنس البشري عن بقية الأجناس الأُخرى، وبتعله يتصف بالتفوّق والسيادة عليها. وكما

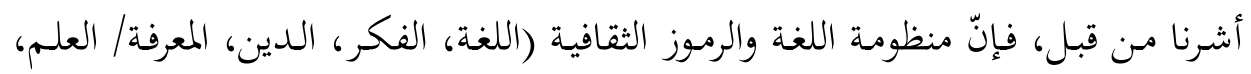

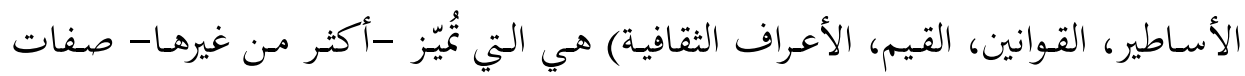
الجنس البشري عن غيره من الأجناس الأُخرى.

r . إنّ الآيتـين الكريمتين المشـار إليهمـا آنفـاً تتحـدثان بوضـوح عن مكانة الإنسـان

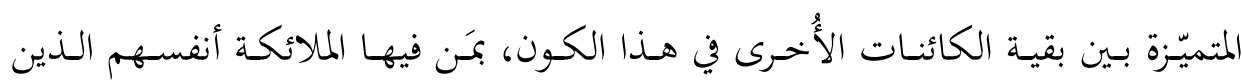

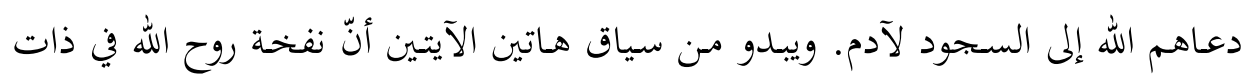
الإنسـان هي السبب الرئيس وراء تبوّؤُ الجهنس البشـري هـذه المكانة الخاصـة في الكون. فالتعبير القـرآين في الآيتـين يوحي بـأنّ الله طلب إلى الملائكة السجود لآدم بعـد -وليس قبل - نفخة روح الإله في صُلْب الذات الآدمية.

إنّ التحليـل الموضـوعي للـنص القـرآي في هـذا الصـدد يشـير بكل وضـوح إلى تفوّق جنس الإنسان وسيادته على بقية الأجناس الأُخرى. فمن جهة، تُرجع العلوم الاجتماعية الحديثة، مثل علم الاجتماع وعلم النفس وعلم الأنثروبولوجيا، تفوّق الجنس البشري على 


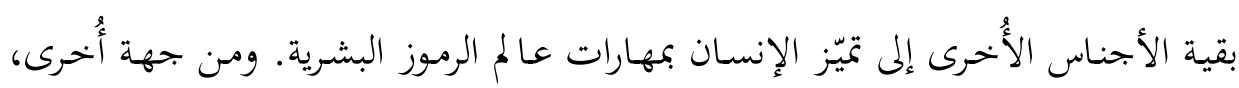
يُُستوحى من النص القرآي أنّ سيادة الإنسان وخلافته في الكون ترتبطان شديد الارتباط بنفخة روح الله في صميم ذات الإنسان. وفي رأينا، فإنّه لا يوجد أيّ تعارض بين هذين

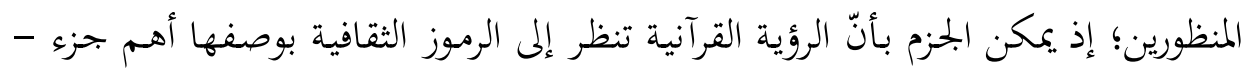

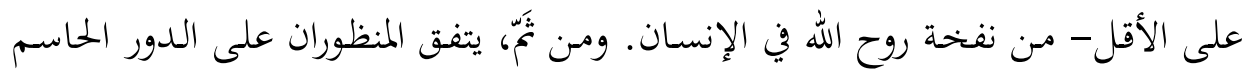
الـذي تؤديـه الرمـوز الثقافيـة في تميّز الجـنس البشـري وتفوّقهـ على بقيـة الكائنسات الحيـة

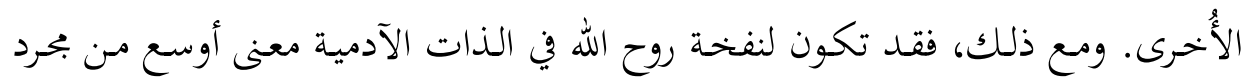
مفهوم الرموز الثقافية؛ أي إنّ نفخة روح الله تشمل كل شيء يُميّز البشر عن غيرهم من ون

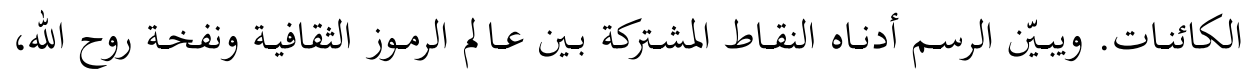
بوصفهما عنصريْن أساسينْ لتميّز الجنس البشري وتفوّقه.

\section{مصدر تميّز الإنسان وتفوّقه}

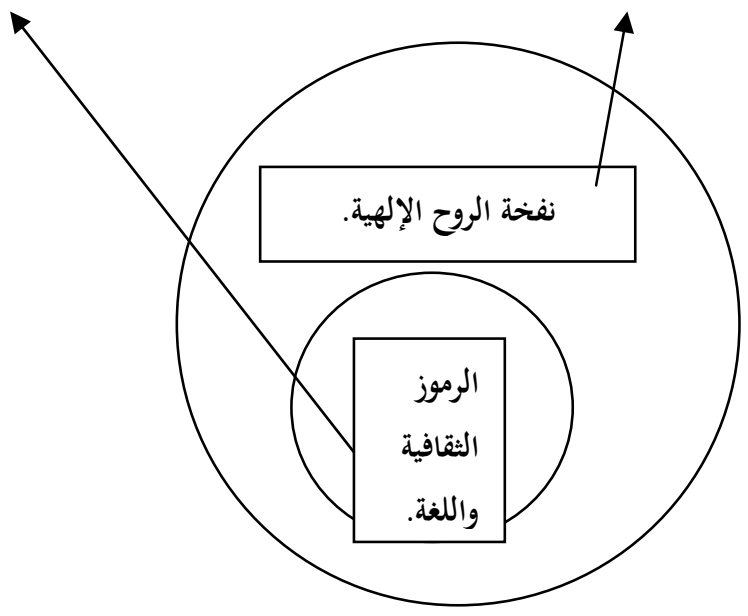

لقد أوضح تحليلنا المنهجي السابق الطبيعة الشاملة لنفخة الروح الإلهية. فنحن نرى

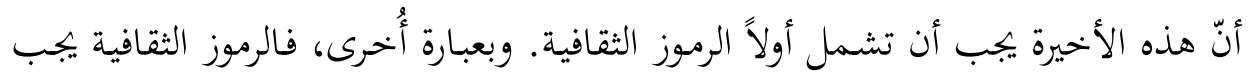

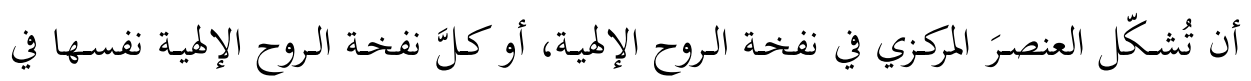


ذات آدم. وبهذه الرؤية تصبح ماهية النفخة الروحية الإلهية أقل غموضاً مُّا كانت عليه في

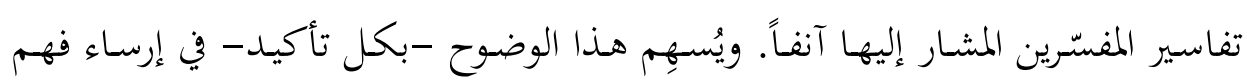

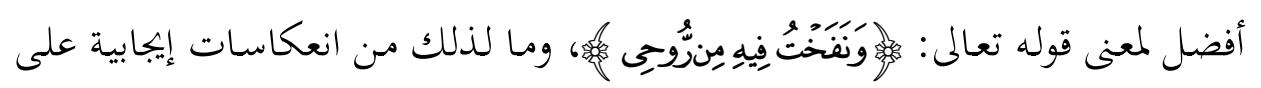
المستوى النظـري للبحـث العلمي في منظومـة الرمـوز الثقافيـة، وعلى المستوى التطبيقي المتمثّّل في دور الرمسوز الثقافيـة في تأهيـل الجـنس البشـري وحـده للخلافـة في هـذا العـالم (الكـون). فقراءتنـا هـه عـن طريق العقل والنقل لـلالات تفضيل السـمع على البصر،

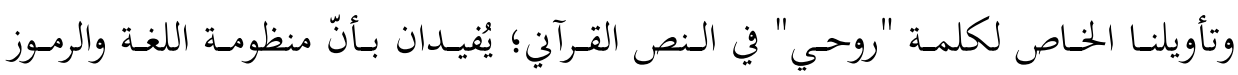
الثقافية هي أهم ما يتميّز به الإنسان عن غيره من الكائنات. 